\title{
Two-dimensional digital photography for child body posture evaluation: standardized technique, reliable parameters and normative data for age 7-10 years
}

\author{
L. Stolinski ${ }^{1,2,3^{*}}$, M. Kozinoga ${ }^{1,2}$, D. Czaprowski ${ }^{4,5}$, M. Tyrakowski ${ }^{6}$ P. Cerny ${ }^{7,8,9}$, N. Suzuki ${ }^{10}$ and T. Kotwicki ${ }^{1}$
}

\begin{abstract}
Background: Digital photogrammetry provides measurements of body angles or distances which allow for quantitative posture assessment with or without the use of external markers. It is becoming an increasingly popular tool for the assessment of the musculoskeletal system. The aim of this paper is to present a structured method for the analysis of posture and its changes using a standardized digital photography technique.

Material and methods: The purpose of the study was twofold. The first one comprised 91 children (44 girls and 47 boys) aged 7-10 (8.2 \pm 1.0$)$, i.e., students of primary school, and its aim was to develop the photographic method, choose the quantitative parameters, and determine the intraobserver reliability (repeatability) along with the interobserver reliability (reproducibility) measurements in sagittal plane using digital photography, as well as to compare the Rippstein plurimeter and digital photography measurements. The second one involved 7782 children (3804 girls, 3978 boys) aged 7-10 (8.4 \pm 0.5$)$, who underwent digital photography postural screening. The methods consisted in measuring and calculating selected parameters, establishing the normal ranges of photographic parameters, presenting percentile charts, as well as noticing common pitfalls and possible sources of errors in digital photography.

Results: A standardized procedure for the photographic evaluation of child body posture was presented. The photographic measurements revealed very good intra- and inter-rater reliability regarding the five sagittal parameters and good reliability performed against Rippstein plurimeter measurements. The parameters displayed insignificant variability over time. Normative data were calculated based on photographic assessment, while the percentile charts were provided to serve as reference values. The technical errors observed during photogrammetry are carefully discussed in this article.

Conclusions: Technical developments are allowed for the regular use of digital photogrammetry in body posture assessment. Specific child positioning (described above) enables us to avoid incidentally modified posture. Image registration is simple, quick, harmless, and cost-effective. The semi-automatic image analysis, together with the normal values and percentile charts, makes the technique reliable in terms of child's posture documentation and corrective therapy effects' monitoring.
\end{abstract}

Keywords: Standardization, Digital photography, Photogrammetry, Percentile charts, Normative data, Primary school children

\footnotetext{
* Correspondence: stolinskilukasz@op.pl

${ }^{1}$ Department of Spine Disorders and Pediatric Orthopedics, University of

Medical Sciences, 28 Czerwca 1956r. no. 135/147, 61-545 Poznan, Poland

${ }^{2}$ Rehasport Clinic, Poznan, Poland

Full list of author information is available at the end of the article
} 


\section{Background}

\section{Human body posture}

Body posture is defined as the alignment of body segments which is considered as an important health indicator [1]. Human body posture is also described as a motor habit accompanying daily activities [2]. Normal human posture is the characteristic of the vertical position which relies on spinal alignment and its position over the patient's head and pelvis [3, 4]. Human body posture undergoes large variability, which depends on age, sex, body growth, environmental factors, and psychophysical status of an individual [5-7]. The accurate description of human body posture represents a topic of interest for the scientists aiming to measure and to document the posture. For the clinicians, posture evaluation plays a role in the global health assessment. On the one hand, faulty posture may result from various disorders, while the posture itself may be even patognomic for certain diseases (ex. spondylolisthesis). On the other hand, incorrect body posture can have negative impact on the overall health, leading to pain or functional disorder, which means that it can affect the quality of life both in childhood and adulthood [8].

The quality of body posture results from individual settings of respective body parts, especially the spine [9] and pelvis [10] alignment in the sagittal plane. The gravity line is defined as the vertical line passing through the center of gravity in the entire body. For a standing subject, the reference posture is described by the relations between the gravity line and body segments [11]. Balanced arrangement of body parts provides the basis for the center of mass. Such arrangement of body parts enables the maintenance of horizontal gaze as well as effective muscle contraction and stretching without unnecessary loss of energy [12]. Diagnostic tools for measuring the sagittal spine curvatures and the pelvis alignment can be used to describe a correct posture while standing [13].

The multitude of methods and diagnostic tools makes it difficult to standardize the assessment of body posture. In addition, there is a lack of a clear range between the traditional and faulty posture-in particular, the number of quantitative posture parameters. Thus, the data on the prevalence of faulty posture is very divergent and based on different diagnostic criteria [14].

The content of the paper fulfills the following objectives: (1) to standardize digital photography technique for posture assessment; (2) to determine the intraobserver reproducibility and the inter-observer reliability of photographic sagittal parameters: sacral slope (SS), lumbar lordosis (LL), thoracic kyphosis (TK), chest inclination (CI), and head protraction (HP); (3) to check the validity of photographic measurements against the Rippstein plurimeter measurements; (4) to analyze the variability of five sagittal photographic angles: SS, LL, TK, CI, HP, and two coronal parameters: Anterior Trunk Symmetry Index (ATSI) and Posterior Trunk Symmetry Index (POTSI) over time (1 week); (5) to present the normative values of sagittal photographic parameters based on photographic assessment of 7782 children aged 7-10; and (6) to discuss common pitfalls and sources of errors in digital photography used in posture evaluation.

\section{Methods \\ Standardization of posture assessment with digital photography}

The use of reliable tools and methods for clinical measurements is the first step towards evidence-based medicine [15] as the foundation of effective and safe clinical practice. Just like any tool, the photographic technique for posture evaluation should be checked and validated before use. Standardization required to assess body posture was performed as part of this study.

\section{Preparing a patient to photogrammetry}

Marking anatomical body landmarks In the procedure below, body posture is assessed without the use of external markers attached to the skin. Dots corresponding to the anatomical body landmarks are drawn on the skin with the use of a non-toxic color pencil. The following body landmarks are marked (Fig. 1):

- The center of the sternal notch
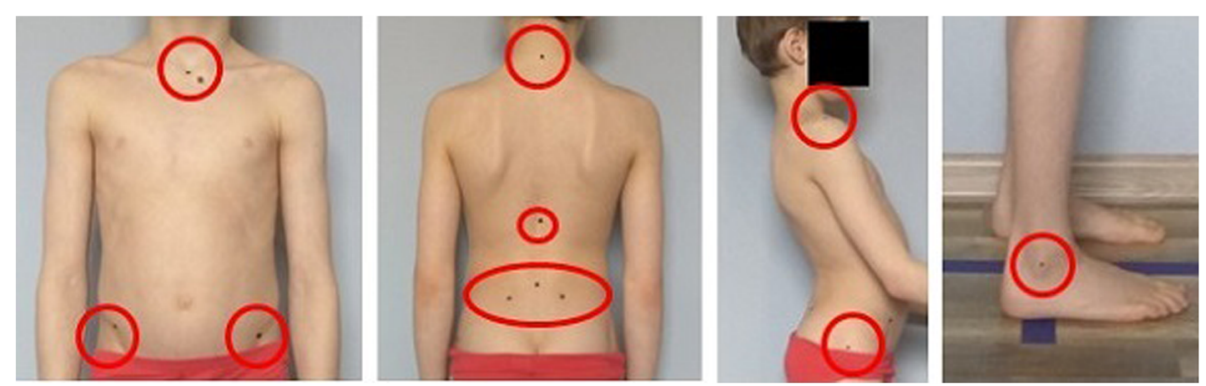

Fig. 1 Anatomical points marked on the body 
- Anterior superior iliac spine (ASIS) - right and left

- Posterior superior iliac spine (PSIS) - right and left

- Spinous process of C7

- The point between T12 and L1 spinous process

- The point between L5 and S1 spinous process

- The center of acromion-right and left

- The center of greater trochanter-right and left

- The center of external malleolus of the ankle joint

Positioning the patient Positioning children during body posture evaluation Standardized procedure for photographic body posture evaluation includes the photos presented in Fig. 2: spontaneous standing frontal posture (2a), sagittal profiles including photos of the left side (2b), left side actively corrected (2c), left side in forward bending ( $2 \mathrm{~d})$, spontaneous standing posture of the back (2e), right side (2f), right side actively corrected $(2 \mathrm{~g})$, right side in forward bending $(2 \mathrm{~h})$, as well as front (2i) and back forward bending (2j).

Positioning children during scoliosis rib and lumbar prominence evaluation In order to document the angle of trunk rotation at different trunk levels, one can take a sequence of photos (5-15) made during forward bending of a child (Fig. 3).

Lower limb positioning in photographic examination The undressed child (wearing the underwear and a narrow bra for girls) is barefoot with its knees extended and the feet hip-width apart. The feet are placed on longitudinal and crosswise lines marked on the ground so that their lateral malleoli are situated over the center of the crosswise line and the feet stay parallel to the longitudinal line (Fig. 4). Most of the upper part of the intergluteal cleft should be uncovered.

Upper limb and head positioning in photographic examination The hair is tied with the use of a hair clip to make the external auditory meatus and the upper body contours visible. Children are asked to look forward at eye level. For the front and back photos, the upper limbs are loosely hanging down. For the lateral photos, in order to uncover the contour of the back, the upper limbs are slightly flexed in the gleno-humeral and the elbow joint at the angle of approx. $10^{\circ}-20^{\circ}$ and $20^{\circ}-30^{\circ}$ respectively. The gleno-humeral joint flexion is performed slowly to avoid any trunk movement, especially the backward trunk hyperextension (Fig. 5). For the front photos taken during forward bending, the upper limbs are kept together and directed forward to the ground as in Adam's test (Fig. 3). For lateral photos made during forward bending, the upper limbs are loosely hanging down (Fig. 2d, h).

\section{Photographic parameters for the frontal plane evaluation}

There are two main photographic parameters for the frontal plane trunk assessment and two for the lower limb assessment. The two trunk parameters are Anterior Trunk Symmetry Index and Posterior Trunk Symmetry Index.

Anterior Trunk Symmetry Index (ATSI)-the parameter is defined as the sum of six indices: three frontal plane asymmetry indices (sternal notch, axilla folds, and waist lines) and three frontal plane height difference indices (acromions, axilla folds, and waist lines). Frontal asymmetry index at sternal notch level (FAI-SN) is calculated by dividing the distance between the center of the sternal notch and the midline by the height of the trunk. The height of the trunk (e) is the vertical distance between the navel and the center of the sternal notch. Frontal asymmetry indexes at axilla level (FAI-A) and at trunk level (FAI-T) are calculated by dividing the difference in the distance between each trunk's edge and the midline $(c-d, a-b)$ by the width of the trunk $(c+d$, a + b). Height indices of trunk asymmetry are calculated by dividing the difference in height at three levels of trunk: HDI-S for shoulders, HDI-A for axillas, and HDI-T for the trunk waistline by the trunk height measured from navel to the center of the sternal notch (e). The shoulder point is the point of intersection at shoulder level with a vertical line from each axilla. ATSI was introduced by Stolinski et al. in 2012 [16] (Fig. 6).

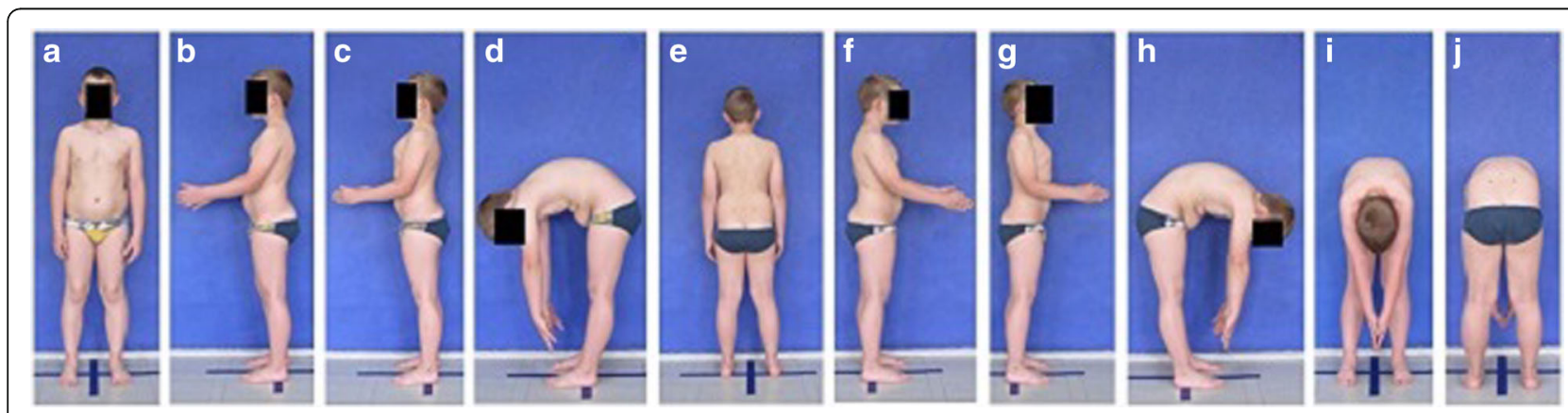

Fig. 2 a-j Standardized positions for posture photogrammetry 


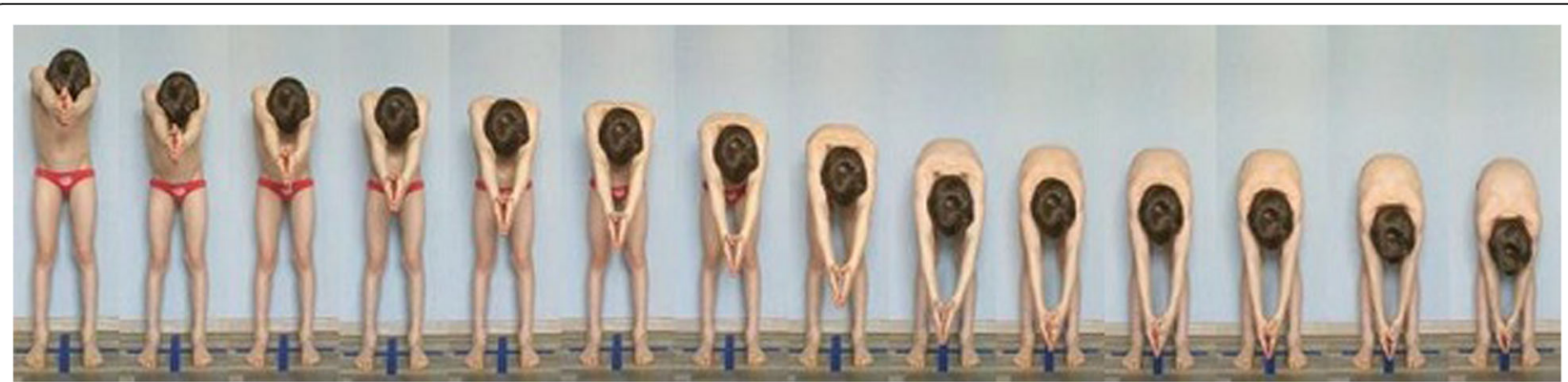

Fig. 3 Photographic documentation of trunk rotation/trunk inclination deformity revealed during Adams' forward bending test (left to right-progressive forward bending)

$$
\begin{aligned}
\mathrm{ATSI} & =(\mathrm{FAI}-\mathrm{SN}+\mathrm{FAI}-\mathrm{A}+\mathrm{FAI}-\mathrm{T}) \\
& +(\mathrm{HDI}-\mathrm{S}+\mathrm{HDI}-\mathrm{A}+\mathrm{HDI}-\mathrm{T})
\end{aligned}
$$

Posterior Trunk Symmetry Index (POTSI)—similarly to ATSI Index, the POTSI parameter is defined as the sum of six indices: three frontal plane asymmetry indices $(C 7$, axilla folds, and waist lines) and three frontal plane height difference indices (acromions, axilla folds, and waist lines). Frontal asymmetry index at C7 level (FAI-C7) is calculated by dividing the distance between the $\mathrm{C} 7$ point and the midline by the height of the trunk. The height of the trunk (e) is the vertical distance between the $\mathrm{C} 7$ and the beginning of gluteal cleft. Frontal asymmetry indexes at axilla level (FAI-A) and trunk level (FAI-T) are calculated by dividing the difference in distance between each trunk's edge and the midline $(\mathrm{c}-\mathrm{d}, \mathrm{a}-\mathrm{b})$ by the width of the trunk $(c+d, a+b)$. Height indices of trunk asymmetry are calculated by dividing the difference in the height at three levels of trunk: HDI-S for shoulders, HDI-A for axillas, and HDI-T for the trunk waistline by the trunk height (e). The shoulder point is the point of intersection at shoulder level with a vertical line from each axilla. POTSI was introduced by Suzuki et al. in 1999 [17, 18] (Fig. 7).

$$
\begin{aligned}
\text { POTSI } & =(\text { FAI-C7 }+ \text { FAI }- \text { A }+ \text { FAI-T }) \\
& +(\text { HDI }-\mathrm{S}+\text { HDI }-\mathrm{A}+\text { HDI-T })
\end{aligned}
$$

The two photographic postural parameters of lower limb frontal plane assessment are tibiofemoral angle and tibiocalcaneal angle.

Tibiofemoral angle (TFA) - the angle between the line drawn from the center of the ankle joint to the center of the knee joint and the line drawn from the center of the knee joint to ASIS of the same lower limb (Fig. 8a) [19, 20].

Tibiocalcaneal angle (TCA) - the angle between a line drawn between the center of the calcaneus and the Achilles tendon, and a second line drawn from the Achilles tendon to the mid-calf of the same lower limb (Fig. 8b) [21].

\section{Photographic parameters for the sagittal plane evaluation}

The following photographic parameters are assumed for the sagittal plane assessment:

Sacral slope angle (SS) - the angle between the vertical line and the line tangent to body contour at the sacral area (Fig. 9a) [22].

Lumbar lordosis angle (LL)-the angle between the line tangent to body contour at the level of T12-L1 spinous processes and the line tangent to body contour at the level of L5-S1 spinous processes (Fig. 9b) [23].

Thoracic kyphosis angle (TK) - the angle between the line tangent to body contour at the level of C7-Th1 spinous processes and the line tangent to body contour at the level of Th12-L1 spinous processes (Fig. 9c) [24].

Chest inclination angle (CI) - the angle between the horizontal line and the line connecting the $\mathrm{C} 7$ spinous process with the point at the anterior neck-anterior thorax junction (Fig. 9d) [25].

Head protraction angle (HP)-the angle between the horizontal line and the line connecting the $\mathrm{C} 7$ spinous process and the external auditory meatus (Fig. 9e) [26].
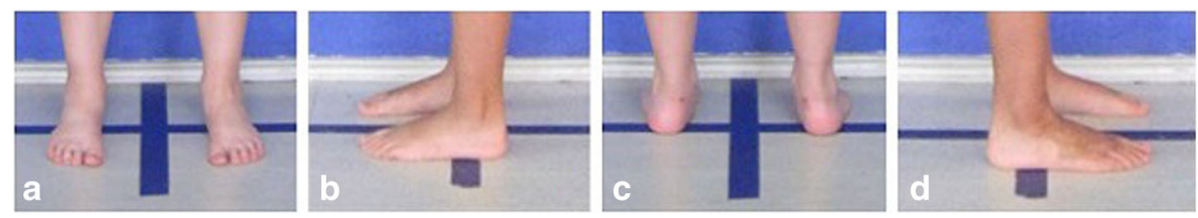

Fig. 4 Feet positioning for posture photographic evaluation: a front view, b lateral left view, c back view, and $\mathbf{d}$ lateral right view 


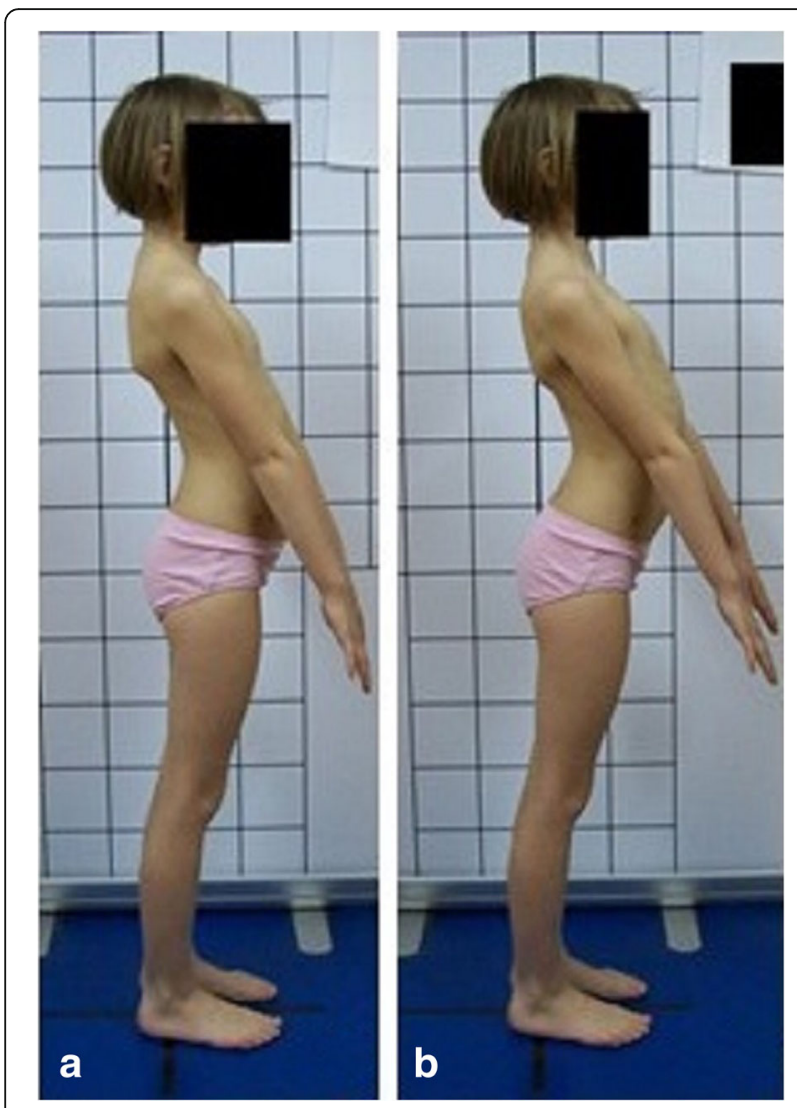

Fig. 5 Child's posture taken for sagittal plane assessment: a spontaneous standing posture, b "actively corrected posture" in this child reveals backward trunk hyperextension which should be avoided; such image points out the importance of children education in what the correct human body posture consists of
Sagittal pelvic tilt (SPT) - the angle between the horizontal line and the line joining the anterior and the posterior superior iliac spine (Fig. 10a) [27].

Trochanter-ankle angle (TA) - the angle between the vertical line drawn from the center of external malleolus of the ankle joint and the line drawn from the center of external malleolus of the ankle joint to the top of the greater trochanter (Fig. 10b).
Acromion-ankle angle (AA) - the angle between the vertical line drawn from the center of external malleolus of the ankle joint and the line drawn from the center of external malleolus of the ankle joint to the center of acromion (Fig. 10c).

Ear-ankle angle (EA) - the angle between the vertical line drawn from the center of external malleolus of the ankle joint and the line drawn from the center of external malleolus of the ankle joint to the external auditory meatus (Fig. 10d).

Enlarged photos of coronal and sagittal parameters are presented in Additional file 1: Appendix 1.

\section{Semi-automatic measurements of postural photographic parameters}

All the abovementioned parameters can be measured manually, manually in ink, on a print or digitally on the monitor screen. To facilitate the measurement, a semiautomatic software named SCODIAC was created [28]. The software is available online and free to download [https://www.ortotika.cz/download/SetupSCODIAC_Full.zip]. The landmarks are manually placed on the screen. Afterwards, the software calculates the values of the required parameters. The initial version of software was checked against x-ray measurements [29]. The current version focused on digital photography images (Fig. 11). Placing the landmarks consists in moving small circles provided at the screen to the required anatomical points manually. The software calculations are automatic. The software explains all functions in a user-friendly way.

\section{Validation of the photographic technique}

We checked the reliability of the photographic technique above. Our objectives in this part of the study were (1) to determine the intra-observer reproducibility and the inter-observer reliability of the photographic sagittal parameters: sacral slope angle (SS), lumbar lordosis angle (LL), thoracic kyphosis angle (TK), chest inclination angle (CI), and head protraction angle (HP) (Fig. 9); and (2) to check the validity of photographic measurements

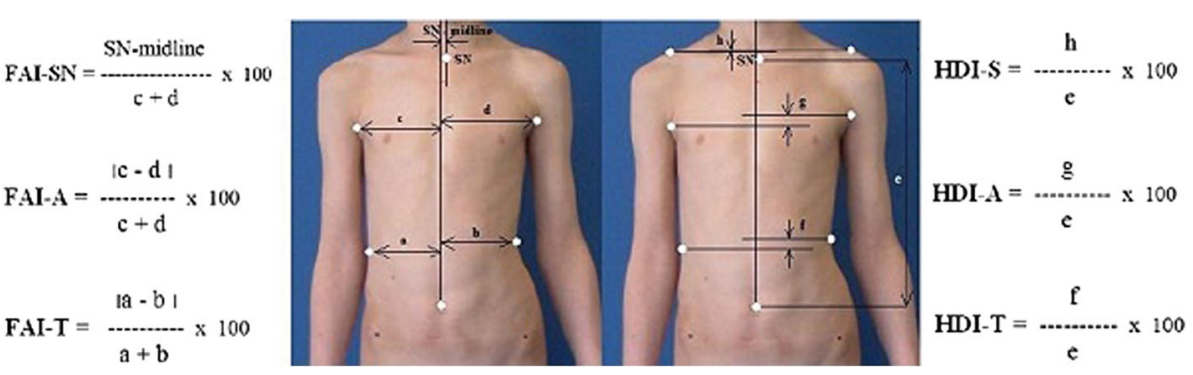

Fig. 6 Diagram illustrating the measurements of ATSI Index 


$$
\begin{aligned}
& \text { FAI-C }=\frac{i}{c+d} \times 100 \\
& \text { FAI-A }=\frac{|c-d|}{c+d} \times 100 \\
& \text { FAI-T }=\frac{|a-b|}{a+b} \times 100
\end{aligned}
$$
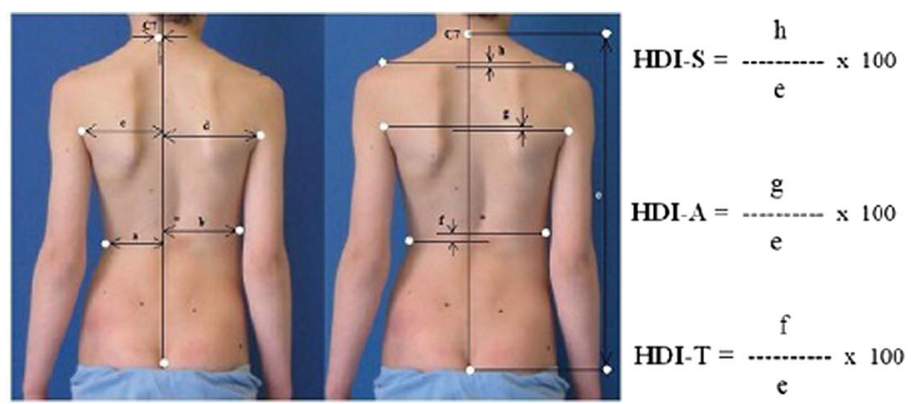

Fig. 7 Diagram illustrating the measurements of POTSI Index

against the Rippstein plurimeter measurements by analyzing correlations between the corresponding angles.

The study group consisted of 91 healthy volunteers (44 girls and 47 boys) aged 7-10 (mean $8.2 \pm 1.0$ years). The exclusion criteria were history of any spine disorder, min. 7-degree ATR value, lower limbs discrepancy, and refusal to participate. Children were photographed in a relaxed (spontaneous, habitual) posture from the left (Fig. 2b) and right side (Fig. 2f). The study was performed in accordance with the 1964 Helsinki Declaration. All studies reported in this chapter were approved by the Institutional Review Board of Poznan University of Medical Sciences (No. 832/11, date 6/10/2011).
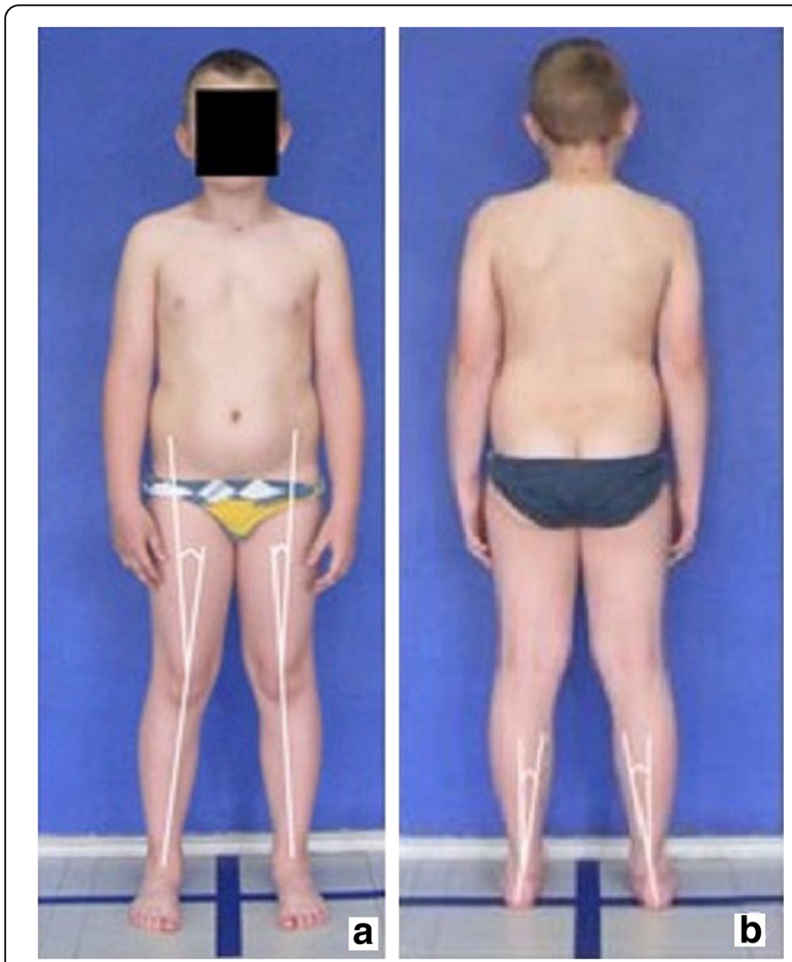

Fig. 8 a Diagram illustrating the measurements of TFA. b Diagram illustrating the measurements of TCA

\section{Intra-observer reproducibility}

One observer (a physiotherapist with 10 years' experience) performed three series of photographic measurements. Each series comprised three measurements, with a 2-day interval between each series. The observer measured the photographic parameters of 30 randomly selected healthy children. Five photographic parameters (SS, LL, TK, CI, and HP) were measured using the aforementioned methodology. The intra-observer reproducibility was quantified by the use of intraclass correlation coefficient (ICC) and standard error for single measurement (SEM) [30].

\section{Inter-observer reliability}

Three observers, physiotherapists with 10,8 , and 2 years' experience respectively, performed three series of photographic measurements. Each series included three measurements, with a 2-day interval between each series. The observer measured photographic parameters of 30 randomly selected healthy children. Five photographic parameters (SS, LL, TK, CI, and HP) were measured using the methodology described above. The interobserver reliability was quantified by the use of intraclass correlation coefficient (ICC) and standard error for single measurement (SEM) [30].

\section{Validation of the photographic technique against Rippstein plurimeter}

In order to determine the correlation of the photographic parameters versus Rippstein plurimeter measurements, three observers measured the sagittal curvatures (sacral slope, lumbar lordosis, and thoracic kyphosis) of 91 children three times with the use of the Rippstein plurimeter (Fig. 12) immediately after the children had the photos taken, one photo from the left side and one photo from the right side, according to standardized conditions described above. The values of the corresponding parameters (photographic thoracic kyphosis angle versus plurimeter thoracic kyphosis angle, etc.) were compared. 

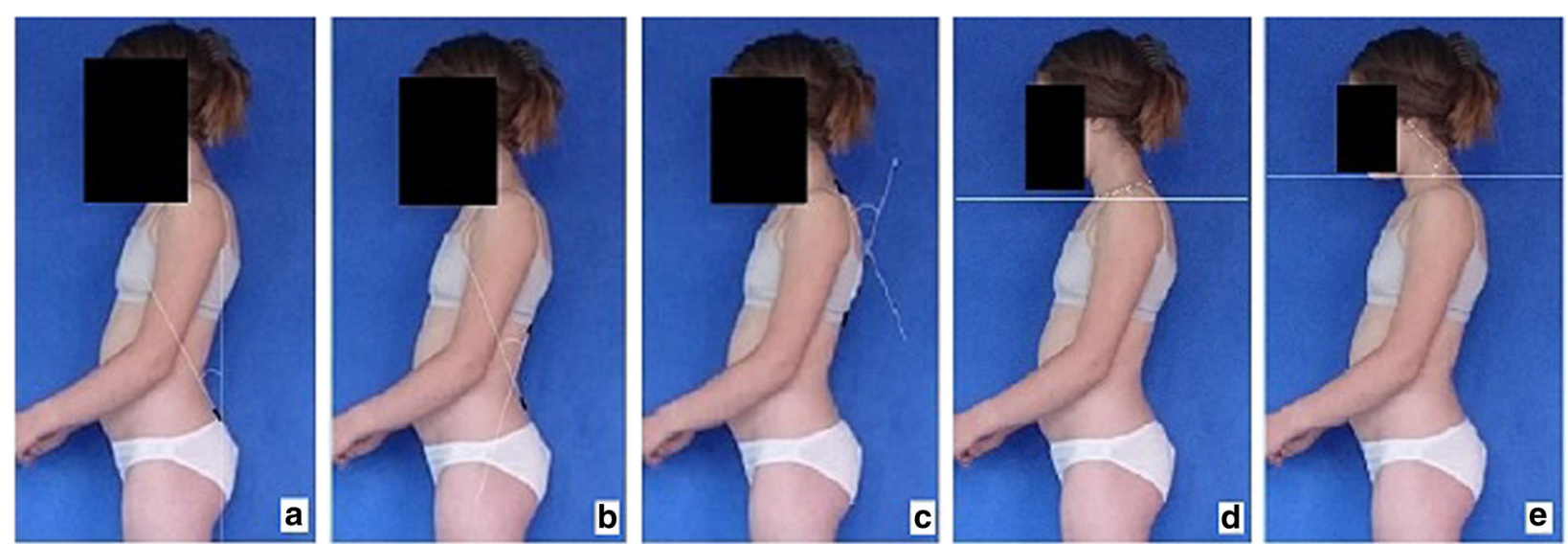

Fig. 9 a Diagram illustrating the measurements of SS. $\mathbf{b}$ Diagram illustrating the measurements of LL. c Diagram illustrating the measurements of TK. $\mathbf{d}$ Diagram illustrating the measurements of $\mathrm{Cl}$. e Diagram illustrating the measurements of HP

Variability of photographic sagittal parameters over time The aim of the second part of the study was to analyze the variability over time (zero time, after $1 \mathrm{~h}$, and after 1 week) of five 2D photographic angles: sacral slope (SS), lumbar lordosis (LL), thoracic kyphosis (TK), chest inclination (CI), and head protraction (HP).

The study group comprised 30 healthy volunteers (13 girls and 17 boys) aged $7-10$ (mean $8.2 \pm$ 1.0 years). The same exclusion criteria as in photographic technique validation XYZ were used. Children were photographed in a standardized relaxed (spontaneous, habitual) posture (Fig. 2b). At each of the three exposures, the digital photographs of the left profile of the body were taken three times one after another within $5 \mathrm{~s}$. The exposure was made (1) at the time zero, (2) $1 \mathrm{~h}$ later, and (3) one week later.
In total, 270 photos were assessed. Five photographic parameters were calculated on each photo.

\section{Variability of photographic coronal parameters over time} The aim of this part of the study was to analyze the variability in time (zero time, after one hour, after one week) of two coronal photographic parameters: ATSI (Anterior Trunk Symmetry Index) (Fig. 6) and POTSI (Posterior Trunk Symmetry Index) (Fig. 7) which serve to evaluate the symmetry of the trunk in coronal plane.

The study group comprised 30 healthy volunteers (13 girls and 17 boys) aged 7-10 (mean $8.1 \pm 1.1$ years). The same exclusion criteria as in photographic technique validation were used. Children were photographed in a standardized relaxed (spontaneous, habitual) posture in the coronal plane. Three digital photographs were taken within 5 s, including the front (Fig. 13) and back (Fig. 14)
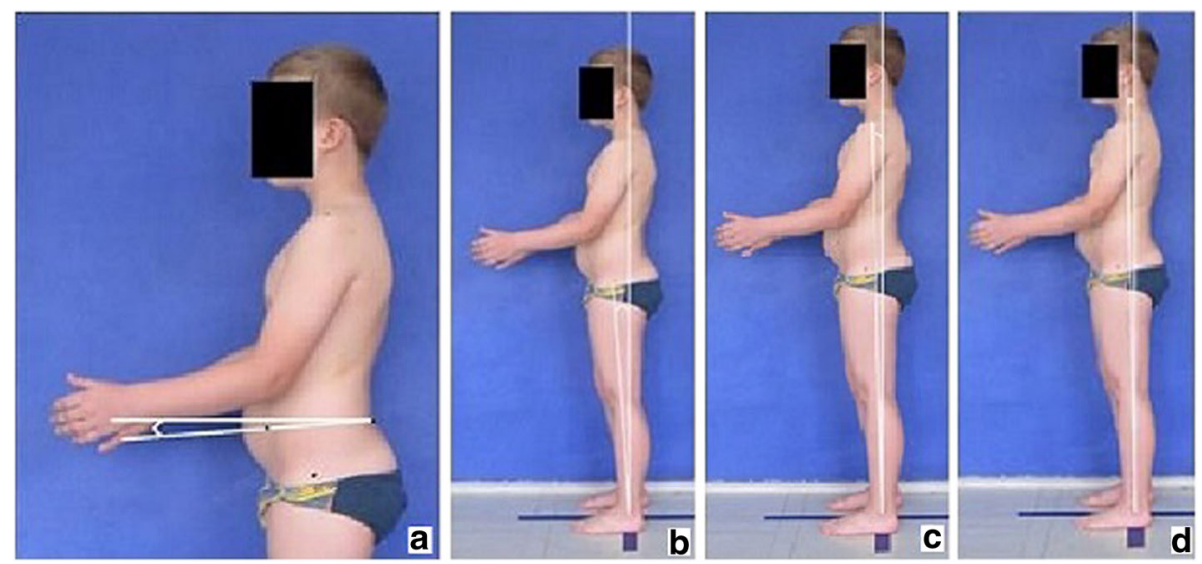

Fig. 10 a Diagram illustrating the measurements of SPT. $\mathbf{b}$ Diagram illustrating the measurements of TA. $\mathbf{c}$ Diagram illustrating the measurements of AA. $\mathbf{d}$ Diagram illustrating the measurements of EA 


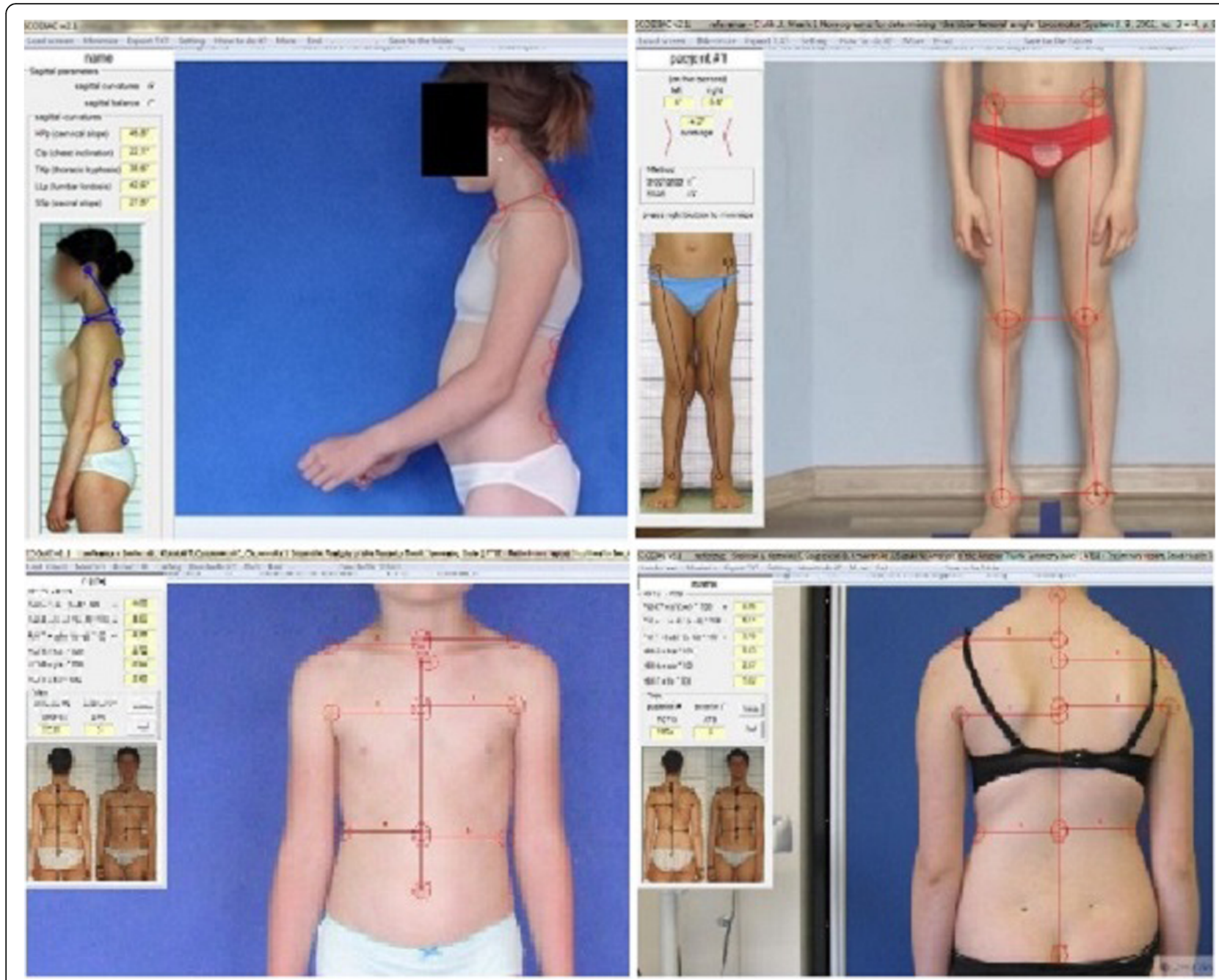

Fig. 11 SCODIAC printscreen images illustrating coronal and sagittal plane parameters
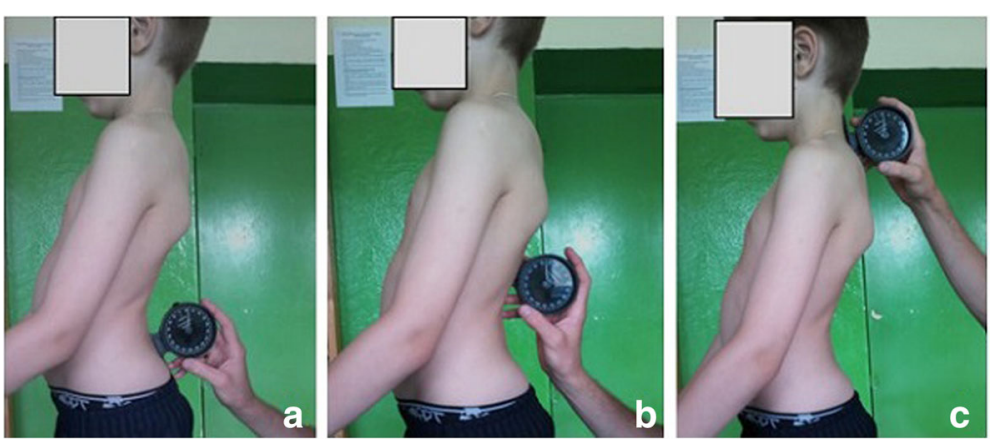

Fig. 12 Areas of application of the Rippstein plurimeter to the patient's spine: a lumbo-sacral junction, $\mathbf{b}$ thoraco-lumbar junction, and $\mathbf{c}$ cervico-thoracic junction. The angular parameters are calculated as the differences between the two positions: lumbar lordosis = a, $\mathbf{b}$; thoracic kyphosis $=\mathbf{b}, \mathbf{c}$ 

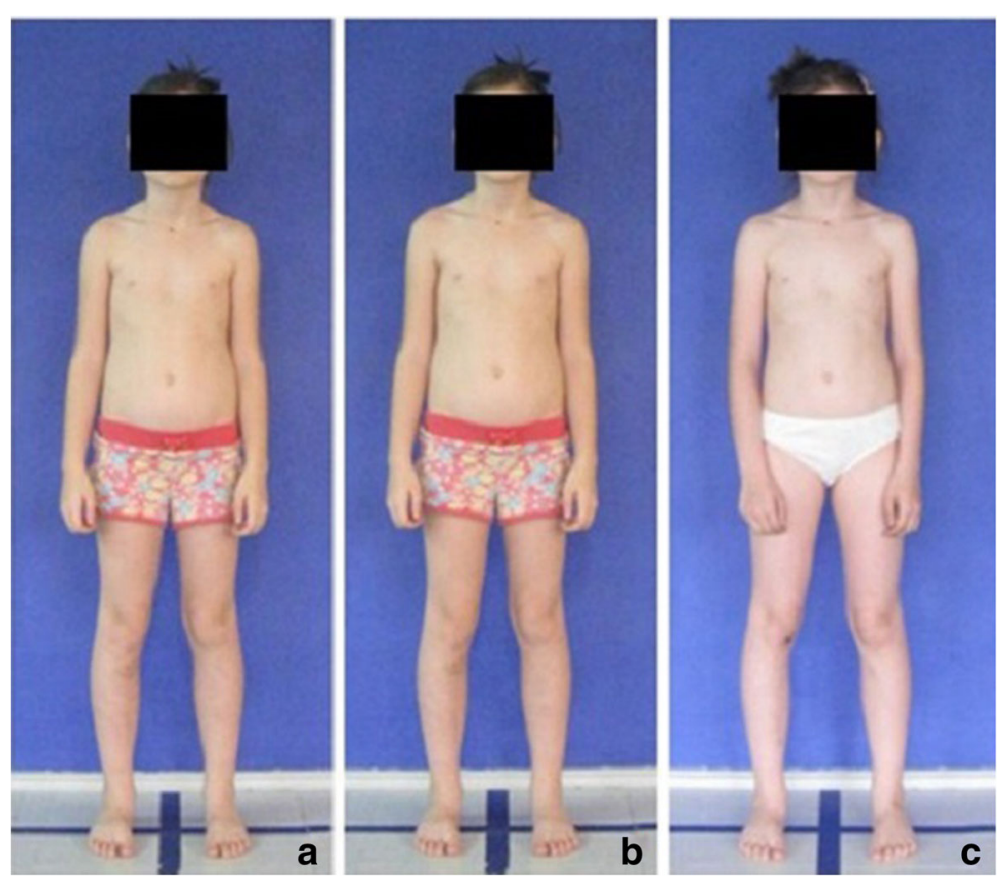

Fig. 13 Positioning of the child during photographic documentation of front view: a zero time, $\mathbf{b}$ after $1 \mathrm{~h}$, and $\mathbf{c}$ after 1 week

view. The same procedure was repeated after $1 \mathrm{~h}$ and after 1 week (540 photos were assessed).

Normative values of sagittal photographic parameters in children aged 7-10

Normative values of sagittal photographic parameters were calculated based on photographic assessment of
7782 children of both sexes, aged 7-10. All photographs were taken respecting the abovementioned procedures.

\section{Statistical analysis}

Statistical analyses were performed using Statistica 10 (StatSoft), Gretl and Microsoft Excel software. Statistical significance level was defined as $P<0.05$. Reliability was determined with the intraclass correlation coefficient
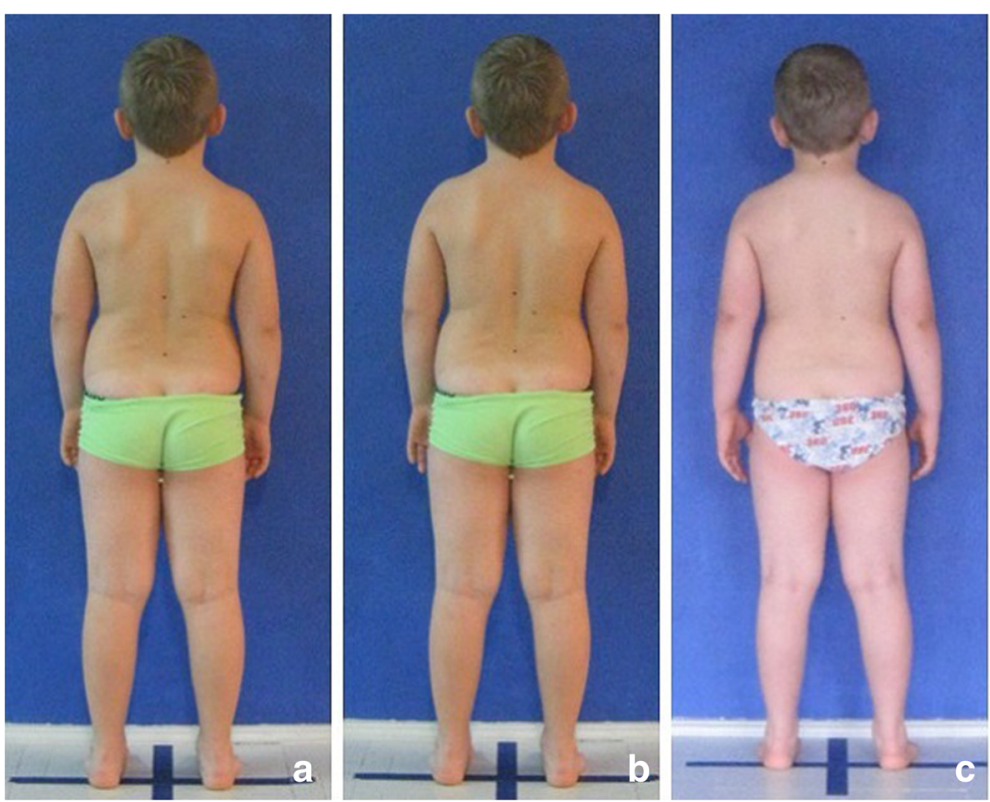

Fig. 14 Positioning of the child during photographic documentation of back view: a zero time, $\mathbf{b}$ after $1 \mathrm{~h}$, and $\mathbf{c}$ after 1 week 
(ICC) by means of the two-way model and Cronbach's alpha. [30, 31]. The scale from Bland and Altman were used in the classification of the reliability values and relationship between plurimeter and photography [30]. ICC values smaller than or equal to 0.20 were considered poor, $0.21-0.40$ fair, $0.41-0.60$ moderate, $0.61-0.80$ good, and 0.81-1 very good [32]. Standard error of measurement (SEM) was measured according to Shrout. [33]. Analysis of variance, homogeneity of variance, normality of distribution, and post hoc tests were used to examine the variation of five photographic sagittal parameters over time.

\section{Results}

Photogrammetry reliability studies

Validation of the photographic technique

Photographic measurements The reliability of the photographic measurements is shown in Table 1. The ICC values for the sacral slope angle, lumbar lordosis angle, thoracic kyphosis angle, chest inclination angle, and head protraction angle revealed very good reliability, with the SEMs of the measurement ranging between 0.7 and 1.3.

Photogrammetry versus plurimeter The correlation of measurements using plurimeter and digital photography
Table 2 Correlation of Rippstein plurimeter versus photographic measurements

\begin{tabular}{llllll}
\hline Variables & ICC & $95 \%$ & $\mathrm{Cl}$ & SEM [ $\left.{ }^{\circ}\right]$ & $P$ value \\
\hline Plurimeter SS_photo SS & 0.93 & 0.89 & 0.95 & 1.2 & 0.712 \\
Plurimeter LL_photo LL & 0.97 & 0.93 & 0.98 & 0.9 & 0.425 \\
Plurimeter TK_photo TK & 0.95 & 0.93 & 0.97 & 1.4 & 0.945
\end{tabular}

ICC intraclass correlation coefficient, Cl confidence interval, SEM standard error of measurement

*Statistically significant difference $(P<.05)$

is shown in Table 2. The ICC values for the sacral slope angle (0.93), lumbar lordosis angle (0.97), and thoracic kyphosis angle (0.95) revealed very good reliability. All ICC values for the three angles reported very good interobserver repeatability, with the SEMs of the measurement ranging between 0.9 and 1.4 .

Variability of photographic sagittal parameters over time There were no significant differences between the measurements $(p>0.05)$ at zero time, after $1 \mathrm{~h}$, and after 1 week in any of the five sagittal photographic parameters. In the case of SS and CI, the 1 week measurement was different to the zero and the 1-h measurement, but the differences were not statistically significant (using analysis of variance and post hoc tests). The results of measurement of both parameters increased with time, so the largest difference was observed between the

Table 1 Reliability of using photographic technique for measuring the sagittal trunk alignment

\begin{tabular}{|c|c|c|c|c|c|c|c|c|c|c|}
\hline \multirow[t]{2}{*}{ Variables } & \multicolumn{5}{|c|}{ Intraobserver reproducibility } & \multicolumn{5}{|c|}{ Interobserver reliability } \\
\hline & ICC & $95 \%$ & $\mathrm{Cl}$ & SEM $\left[^{\circ}\right]$ & $P$ value & ICC & $95 \%$ & $\mathrm{Cl}$ & SEM [ $\left[^{\circ}\right]$ & $P$ value \\
\hline \multicolumn{11}{|c|}{ Left side of the body } \\
\hline SS & 0.93 & 0.88 & 0.97 & 1.0 & 0.957 & 0.93 & 0.86 & 0.97 & 0.9 & 0.658 \\
\hline $\mathrm{LL}$ & 0.97 & 0.95 & 0.99 & 1.0 & 0.975 & 0.97 & 0.95 & 0.99 & 1.0 & 0.987 \\
\hline TK & 0.93 & 0.87 & 0.96 & 1.2 & 0.974 & 0.94 & 0.89 & 0.97 & 0.9 & 0.811 \\
\hline $\mathrm{Cl}$ & 0.96 & 0.92 & 0.98 & 0.7 & 0.953 & 0.92 & 0.83 & 0.96 & 0.9 & 0.540 \\
\hline $\mathrm{HP}$ & 0.90 & 0.83 & 0.95 & 1.0 & 0.990 & 0.84 & 0.74 & 0.92 & 1.2 & 0.984 \\
\hline \multicolumn{11}{|c|}{ Right side of the body } \\
\hline SS & 0.93 & 0.88 & 0.97 & 1.0 & 0.952 & 0.92 & 0.86 & 0.96 & 1.1 & 0.954 \\
\hline $\mathrm{LL}$ & 0.96 & 0.93 & 0.98 & 1.2 & 0.936 & 0.96 & 0.92 & 0.98 & 1.1 & 0.852 \\
\hline TK & 0.91 & 0.85 & 0.95 & 1.3 & 0.990 & 0.92 & 0.86 & 0.96 & 1.2 & 0.726 \\
\hline $\mathrm{Cl}$ & 0.93 & 0.87 & 0.96 & 0.9 & 0.931 & 0.88 & 0.79 & 0.94 & 1.1 & 0.689 \\
\hline $\mathrm{HP}$ & 0.94 & 0.89 & 0.97 & 0.7 & 0.989 & 0.85 & 0.75 & 0.92 & 1.0 & 0.913 \\
\hline \multicolumn{11}{|c|}{ Mean of the left and right side of the body } \\
\hline SS & 0.95 & 0.91 & 0.97 & 0.9 & 0.977 & 0.94 & 0.89 & 0.97 & 0.9 & 0.836 \\
\hline $\mathrm{LL}$ & 0.97 & 0.95 & 0.98 & 1.0 & 0.952 & 0.98 & 0.95 & 0.99 & 0.9 & 0.936 \\
\hline TK & 0.93 & 0.88 & 0.97 & 1.1 & 0.986 & 0.92 & 0.86 & 0.96 & 0.9 & 0.777 \\
\hline $\mathrm{Cl}$ & 0.96 & 0.92 & 0.98 & 0.7 & 0.950 & 0.92 & 0.84 & 0.96 & 0.9 & 0.622 \\
\hline HP & 0.94 & 0.89 & 0.97 & 0.8 & 0.995 & 0.89 & 0.80 & 0.94 & 1.0 & 0.979 \\
\hline
\end{tabular}


Table 3 Variability of sagittal and frontal parameters over time

\begin{tabular}{|c|c|c|c|c|c|c|c|c|c|c|c|c|c|c|}
\hline \multirow[t]{2}{*}{ Measurements } & \multicolumn{2}{|l|}{ SS } & \multicolumn{2}{|l|}{ LL } & \multicolumn{2}{|l|}{ TK } & \multicolumn{2}{|l|}{$\mathrm{Cl}$} & \multicolumn{2}{|l|}{$\mathrm{HP}$} & \multicolumn{2}{|l|}{ ATSI } & \multicolumn{2}{|l|}{ POTSI } \\
\hline & Mean & SD & Mean & SD & Mean & SD & Mean & SD & Mean & SD & Mean & SD & Mean & SD \\
\hline Zero time & 24.7 & 7.0 & 41.7 & 9.5 & 44.5 & 6.7 & 27.1 & 7.1 & 53.3 & 3.1 & 21.6 & 11.6 & 21.3 & 10.0 \\
\hline After $1 \mathrm{~h}$ & 25.3 & 7.2 & 42.0 & 8.3 & 43.6 & 7.6 & 27.6 & 7.5 & 52.8 & 5.8 & 21.8 & 11.4 & 21.9 & 10.6 \\
\hline After 1 week & 26.8 & 8.1 & 43.0 & 9.1 & 45.0 & 8.9 & 29.3 & 6.8 & 52.8 & 5.1 & 20.1 & 8.8 & 18.3 & 6.1 \\
\hline$P$ & 0.533 & & 0.854 & & 0.786 & & 0.478 & & 0.926 & & 0.798 & & 0.288 & \\
\hline
\end{tabular}

Mean mean value of three measurements, $S D$ standard deviation of three measurements

*Statistically significant difference $(P<.05)$

measurement carried out in time zero and 1 week later. In case of the remaining three parameters (TK, LL, HP), we could not find such a trend (Table 3 ).

Variability of photographic coronal parameters over time There was no statistically significant difference between measurements $(p>0.05)$ for ATSI in zero time, after $1 \mathrm{~h}$, and after 1 week. There was no statistically significant difference between measurements $(p>0.05)$ for POTSI parameters in zero time, after $1 \mathrm{~h}$, and after 1 week (Table 4). A slight tendency regarding the difference between the 1-week measurement and the zero and 1 -h measurement was not statistically significant. This observation needs further study in a bigger sample ( $p$ values in post hoc tests were between 0.15 and 0.30 ).

Normative values of sagittal photographic parameters for children 7-10 Five sagittal photographic parameters (SS, LL, TK, CI, HP) were measured for each child. The data was analyzed separately for boys and girls and for each year of age, ranging from 7 to 10. Numerical values based on the tables (Additional file 2: Appendix 2A) and percentile charts for sex and age (Additional file 2: Appendix 2B) are presented in Additional file 2: Appendix 2. Table 4 contains the exemplary numerical values of the five photographic parameters (all values presented in degrees).

Table 4 Exemplary table based on numerical values for 7-year-old girls $(N=1083)$

\begin{tabular}{llllll}
\hline Percentile & SS & $\mathrm{LL}$ & $\mathrm{TK}$ & $\mathrm{Cl}$ & $\mathrm{HP}$ \\
\hline 97 & 44 & 52 & 62 & 41 & 71 \\
90 & 39 & 45 & 55 & 36 & 66 \\
75 & 33 & 37 & 48 & 32 & 63 \\
50 & 27 & 29 & 42 & 27 & 58 \\
25 & 22 & 23 & 35 & 22 & 54 \\
10 & 17 & 18 & 28 & 18 & 49 \\
3 & 12 & 13 & 23 & 14 & 45 \\
\hline
\end{tabular}

Pitfalls and sources of errors in photogrammetry used for posture evaluation Errors may occur during photographic examination and photography evaluation. Attention should be paid to prepare and position the child according to the protocol. The incorrect preparation or positioning is illustrated below with the examples identified within our study group of 7782 children participating in the local school screening program. In total, 46,595 digital photos were analyzed.

The following problems were noted and are reported below in the following way: (1) type of error and (2) consequence for posture assessment. Figures are illustrating the following:

- Protraction of the shoulders-the upper limbs cover the body contours and anatomical points (Fig. 15)

- Incorrect head position and gaze direction-impact on cervical spine parameters (Fig. 16)

- Inability to adopt spontaneous relaxed posture-impact on lumbar lordosis and thoracic kyphosis angles (Fig. 17)

- Hair covering the body contours-impossibility of measuring photographic parameters (Fig. 18)

- Gluteal cleft covered with underpants-impossible calculation of POTSI index (Fig. 19)

- Bra or swimsuit with limited body contact and obscuring the trunk-sagittal angles design and calculation not possible (Fig. 20)

- One-leg standing-impact on coronal plane symmetry (Fig. 21)

- Incorrect rotational foot positioning-introduction of rotation to the whole body (Fig. 22)

- Digital camera not level-possible photographic parameters modification (Fig. 23)

- Limited communication with the child can be treated as a contraindication for photographical measurements-standardized position not possible (Fig. 24)

- Insufficient image sharpness-difficulties with photographic angle measurement (Fig. 25)

These errors can influence the photographic evaluation and should be avoided. 


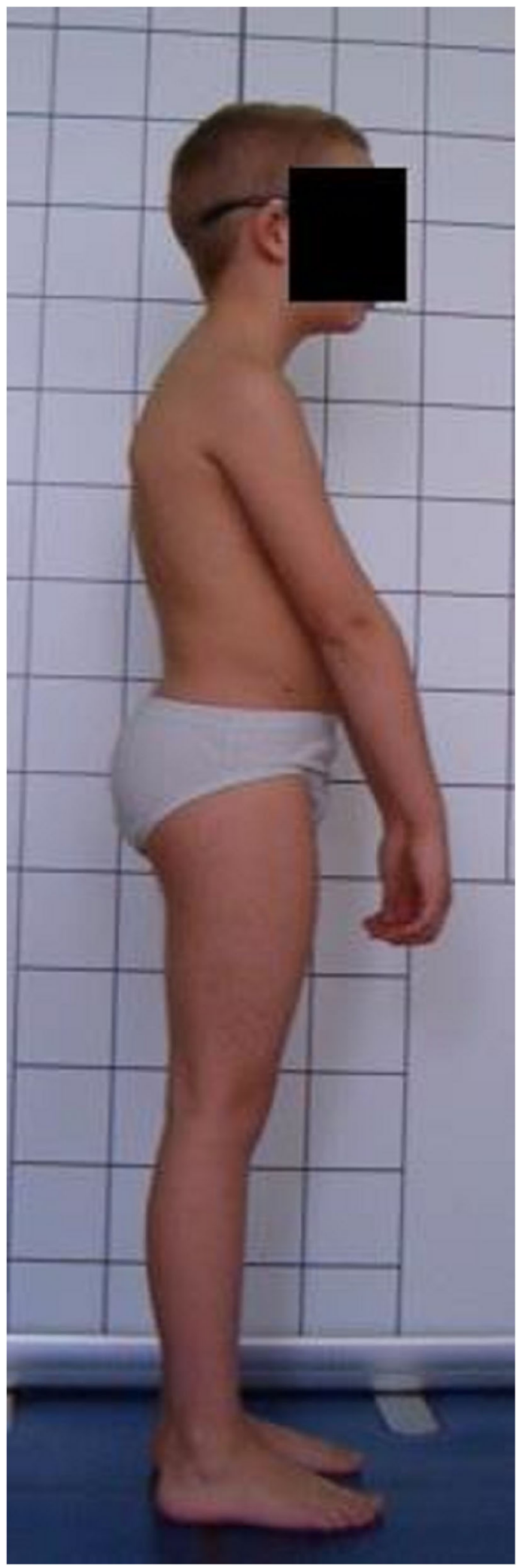

Fig. 15 Technical error-protraction of the shoulders

\section{Discussion}

Radiological assessment as the current gold standard for scoliosis evaluation but not for child body posture evaluation

The radiological imaging remains the gold standard for idiopathic scoliosis (IS) diagnosis and evaluation [34-37]. It enables the primary and secondary curves identification, Cobb angle measurement, axial vertebral rotation assessment, and Risser sign grading. It differentiates the idiopathic scoliosis from the congenital one. However, for the large cohort studies or for the school screening purpose, the children are not exposed to radiography because of the radiation risk $[38,39]$. In the screening conditions, the suspicion of idiopathic scoliosis is detected with manual anthropometric devices, such as the scoliometer [40-43] or smartphone with a specific device [44-46]. The basic method of school screening for idiopathic scoliosis is a clinical examination in the forward bending position (Adam's test) with the use of scoliometer [47, 48]. Surface topography methods based on computerized image capturing and digitally calculated parameters are also proposed for the evaluation of patients suffering from idiopathic scoliosis. These techniques utilize raster stereography based on distortion of a grid projected onto the back [49-51] or body scanning using light beam and its distortion analysis $[49,52,53]$.

Evaluation of physical deformity developing in idiopathic scoliosis presents some common areas together with the body shape evaluation in postural disorders. Similar diagnostic tools are often used. In children, it is especially important to apply the techniques which do not involve exposure to $x$-ray radiation. Several methods have been proposed for body posture assessment: simple photographic techniques and plumbline measures [54-57], goniometers, inclinometers and linear devices [58-60], computer-assisted methods including electrogoniometers [61], electromagnetic movement systems [62, 63], computer-assisted digitization systems [64-66], or 3D ultrasound-based motion analysis device [67]. Finally, digital photography is gaining grounds in the assessment of trunk alignment [68].

\section{Overview of photographic parameters proposed for posture evaluation}

Photographic parameters for posture evaluation were presented by several authors. The parameters proposed in this study were selected based on the authors' personal experience and the careful analysis of previous publications.

Canales et al. [69] reported the following posterior and sagittal parameters: head position, thoracic kyphosis, lumbar lordosis, pelvic inclination, and knee position 

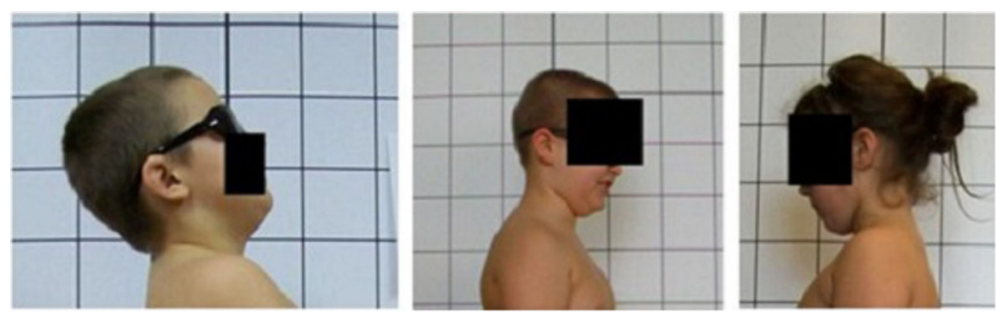

Fig. 16 Technical error-incorrect head position and/or gaze direction

together with the following anatomical points to be considered: scapulas, shoulders, and ankles (Fig. 26).

Cerrutto et al. [70] reported the following anterior, posterior, and sagittal parameters: P1, P2, L1, L2, L3, $\mathrm{AR}$, and $\mathrm{AL}$ angles which were measured based on the lines drawn from the anatomical points: superior and inferior scapular angles, vertical lines related to ear lobe, acromion and scapular prominence, and vertical lines related to manubrium and coracoid process (Fig. 27).

Pausić et al. [71] proposed assessment based on the following anatomical points: head and neck, trunk, pelvis, knee joints, and ankle joints (for the coronal plane) or head and neck, trunk, pelvis, and knee joints for the sagittal plane (Fig. 28).

Penha et al. [8] reported the following posterior and sagittal parameters: lumbar lordosis, thoracic kyphosis, pelvic inclination, head position, and lateral spinal deviations based on anatomical points to be considered (Fig. 29).

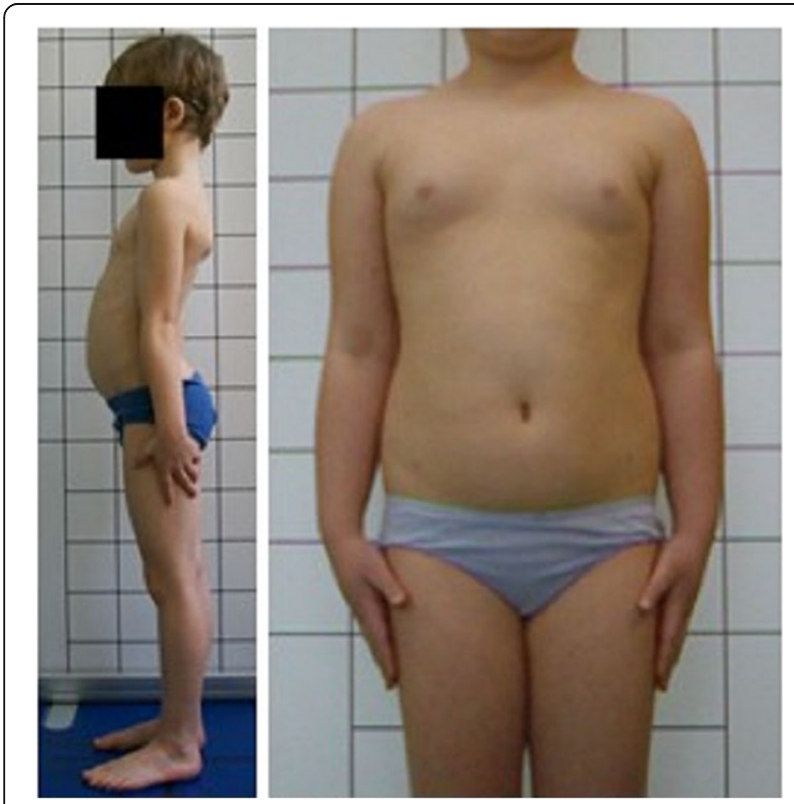

Fig. 17 Technical error-lack of spontaneous relaxed posture
Ruivo et al. [72] reported the following sagittal parameters: head angle, cervical angle, and shoulder angle (Fig. 30).

Sacco et al. [73] reported the following sagittal parameters: tibiotarsal angle, knee extension/flexion angle, Q angle, and subtalar angle (Fig. 31).

Canhadas et al. [74] proposed the following anatomical points to be considered: external orbicularis, commissura labiorum, acromioclavicular joint, sternoclavicular joint, ear lobe, antero-superior iliac spines, posterosuperior and postero-inferior iliac spines, inferior angles of the scapula, olecranon central region, and popliteal line. In addition, the following angles were evaluated: bilateral foot inclination, forward inclination of the fibula, knee angle, cervical lordosis, thoracic kyphosis, lumbar lordosis, knee flexor, tibiotarsal angle, forward head position, and sternal angles (Fig. 32).

Matamalas et al. [75] reported the following posterior parameters: waist height angle, waist angle, and waistline distance ratio (Fig. 33).

Matamalas et al. [76] published the following anterior and posterior parameters: trapezium angle, shoulder height angle, and axilla height angle (Fig. 34).

\section{Current opinions on digital photography technique}

Digital photography completed with analyzing software can be viewed as digital photogrammetry and can be found in several areas of life and technology: architecture, psychology, medicine, rehabilitation, and other fields [77-80]. For the purpose of posture assessment, this technique is easy to access and cost-effective [81, 82]. The technique provides measurement of body angles or distances, which allows for a quantitative posture assessment. Remaining non-invasive, digital photography is becoming an increasingly popular tool for assessing the musculoskeletal system, including the sagittal and coronal curvatures of the spine, in both clinical practice and research [83, 84]. In recent years, the photographic technique has been used to assess the posture of healthy and unhealthy children and adults [69, 74, 85]. Digital photography was applied to assess body posture of children carrying heavy backpacks [86], to evaluate the quality of posture while standing $[87,88]$ and siting $[89]$, or 

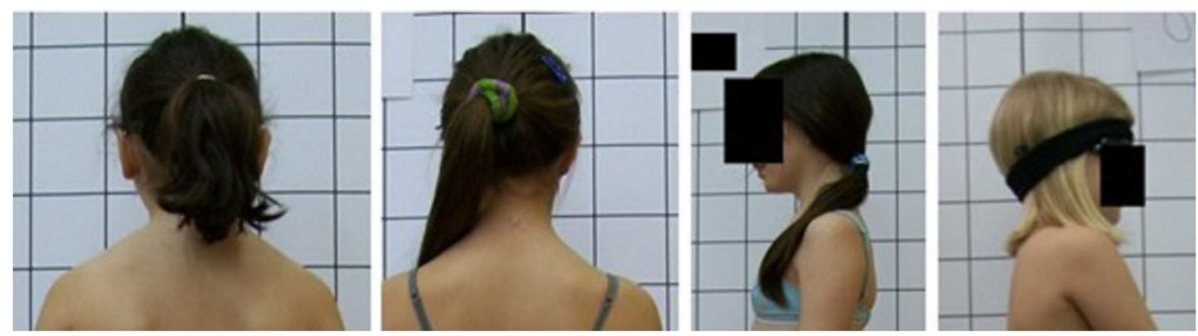

Fig. 18 Technical error-body contours covered by hair

for quantifying the foot shape [90]. Several studies described usefulness of the photographic technique to assess patients with idiopathic scoliosis [75, 91-94].

\section{Technical procedures of posture photogrammetry Camera resolution}

Different resolutions of digital cameras were used in the previous studies, ranging from 2.0 megapixels (Mpx) [73], 4.1 Mpx [95, 96], through 5.1 Mpx [84], 6.0 Mpx [81], 6.3 Mpx [97] to 7.2 Mpx [98]. For this study, CANON POWER SHOT A590 IS, 1/2.5 CCD matrix, 8.3 megapixels, 35-140-mm lens (Canon Incorporation, Tokyo, Japan) was used. The resolution of $1600 \times 1200$ [2 Mpx] provided sufficient photo quality [99].

\section{Camera position-distance and height}

In previous photographic studies, the distance between the camera and the object was reported to be $173 \mathrm{~cm}$ [97, 100], $300 \mathrm{~cm} \mathrm{[73,} \mathrm{81,} \mathrm{95,} \mathrm{101],} \mathrm{or} 400 \mathrm{~cm}[55]$. The camera was positioned at the height of $70,127,80$ or $90 \mathrm{~cm}$ [81], while other authors set the camera by centering the lens at half of the child's height [81, 95, 98]. In our previous experiments, the camera was placed on a stabile tripod at the height of $90 \mathrm{~cm}$ and the distance of $300 \mathrm{~cm}$. These settings were previously suggested for children aged 7-10 [81, 98]. Such a combination of distance and height enabled covering the whole silhouette without moving the camera [12].
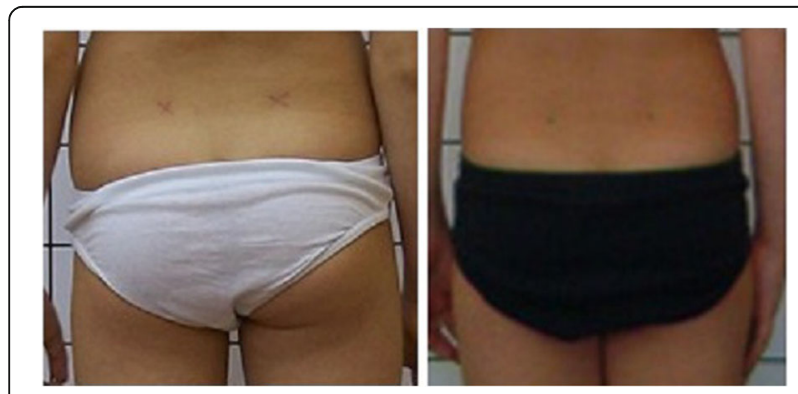

Fig. 19 Technical error—gluteal cleft upper contour covered by underpants

\section{Child positioning}

Some authors proposed to practice the photographic examination of the standing child wearing casual clothes, sportswear (shorts and a T-shirt) [87], just shorts [64], or the swimsuit [102]. Unfortunately, the clothes may slightly distort the body contour. Producing and registering images of undressed children seems to be a potential challenge for posture photogrammetry. Nowadays, it involves both the imperative to adopt procedures respecting individual sensitivity and the protection of image processing and storing. Yet, here we are, proposing the evaluation of the child body posture without any T-shirt, thigh or socks, wearing only underwear and bra [103], which is not

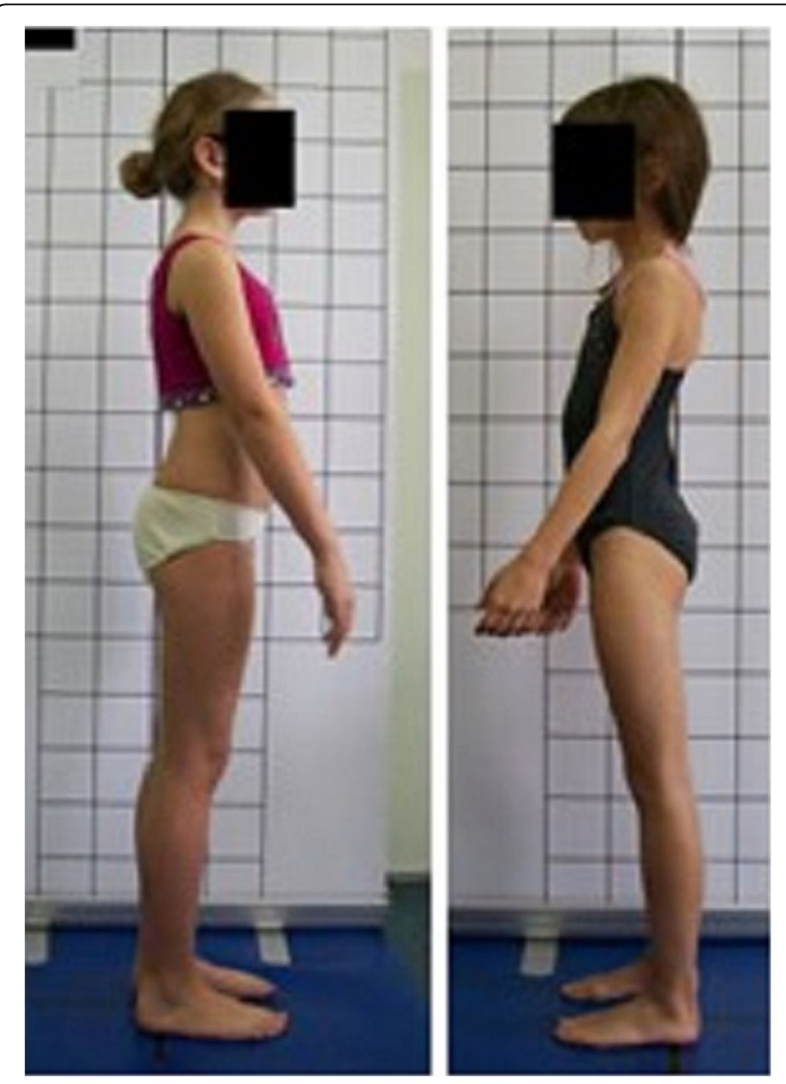

Fig. 20 Technical error-the trunk obscured by bra or swimsuit 


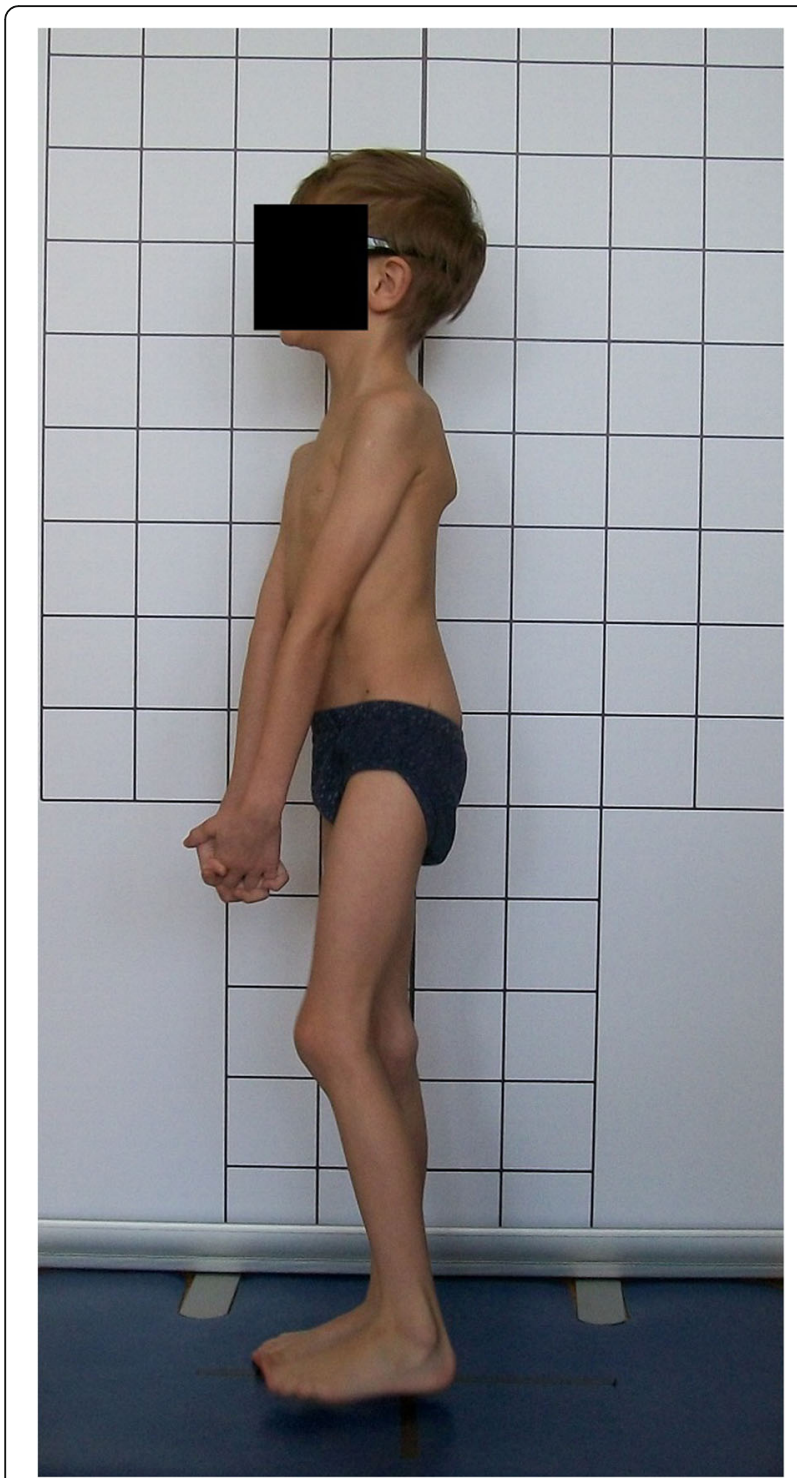

Fig. 21 Technical error-one-leg standing

commonly accepted in our society (with individual cases of parents refusal noted). However, the local cultural background should be considered. Longer hair of the person examined should be tied or curled with a clip so as not to cover the external auditory meatus or neck contour.

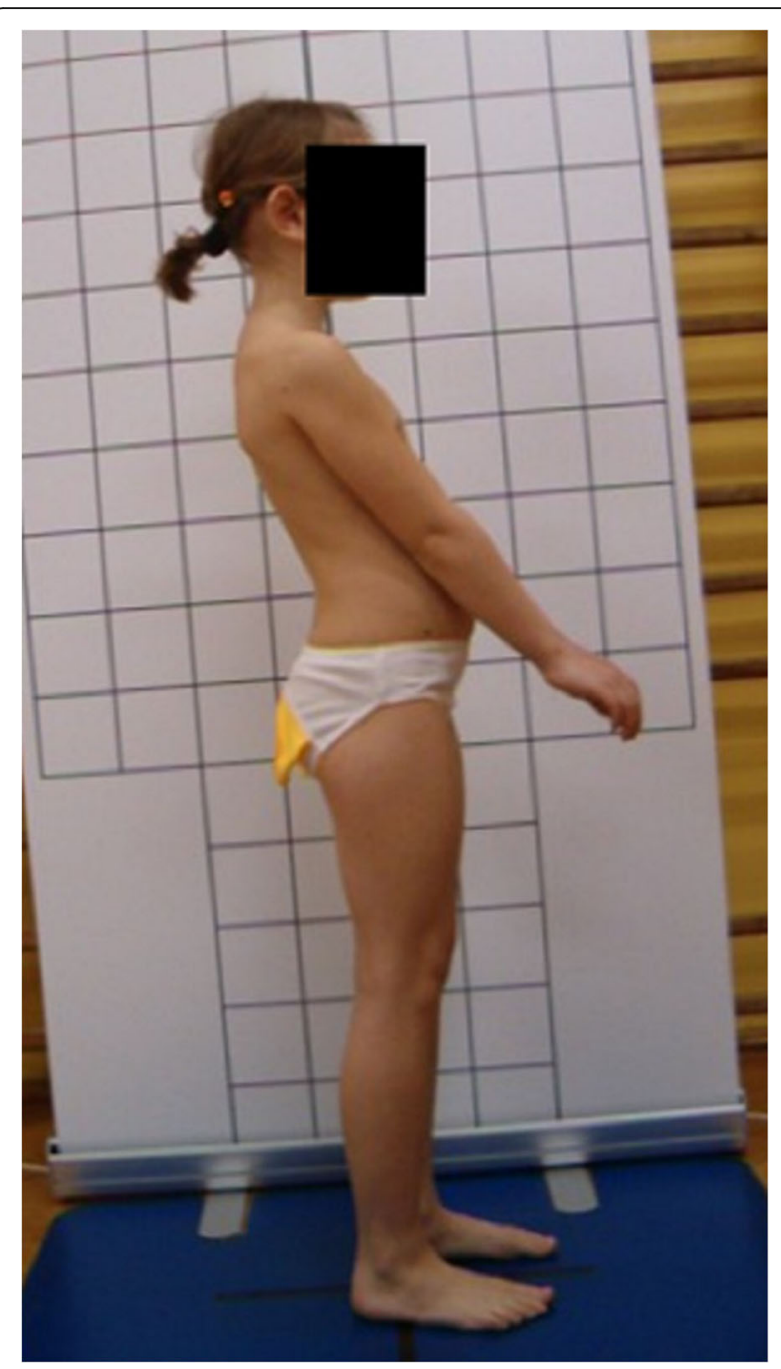

Fig. 23 Technical error_digital camera not leveled

\section{Lower limb positioning - the feet}

In previous studies, some authors proposed to set the feet at the 30-degree external rotation in drawn triangles [97] or freely within the defined field lines [84]. In our observation, the 30-degree external rotation of the feet may undesirably impact the position of other parts of the body, especially the ankle joint in relation to the vertical projection of the quadrangle support.
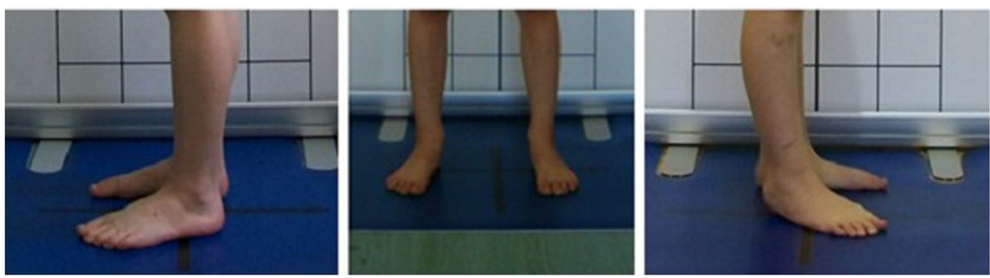

Fig. 22 Technical error-incorrect feet position unparalleled 


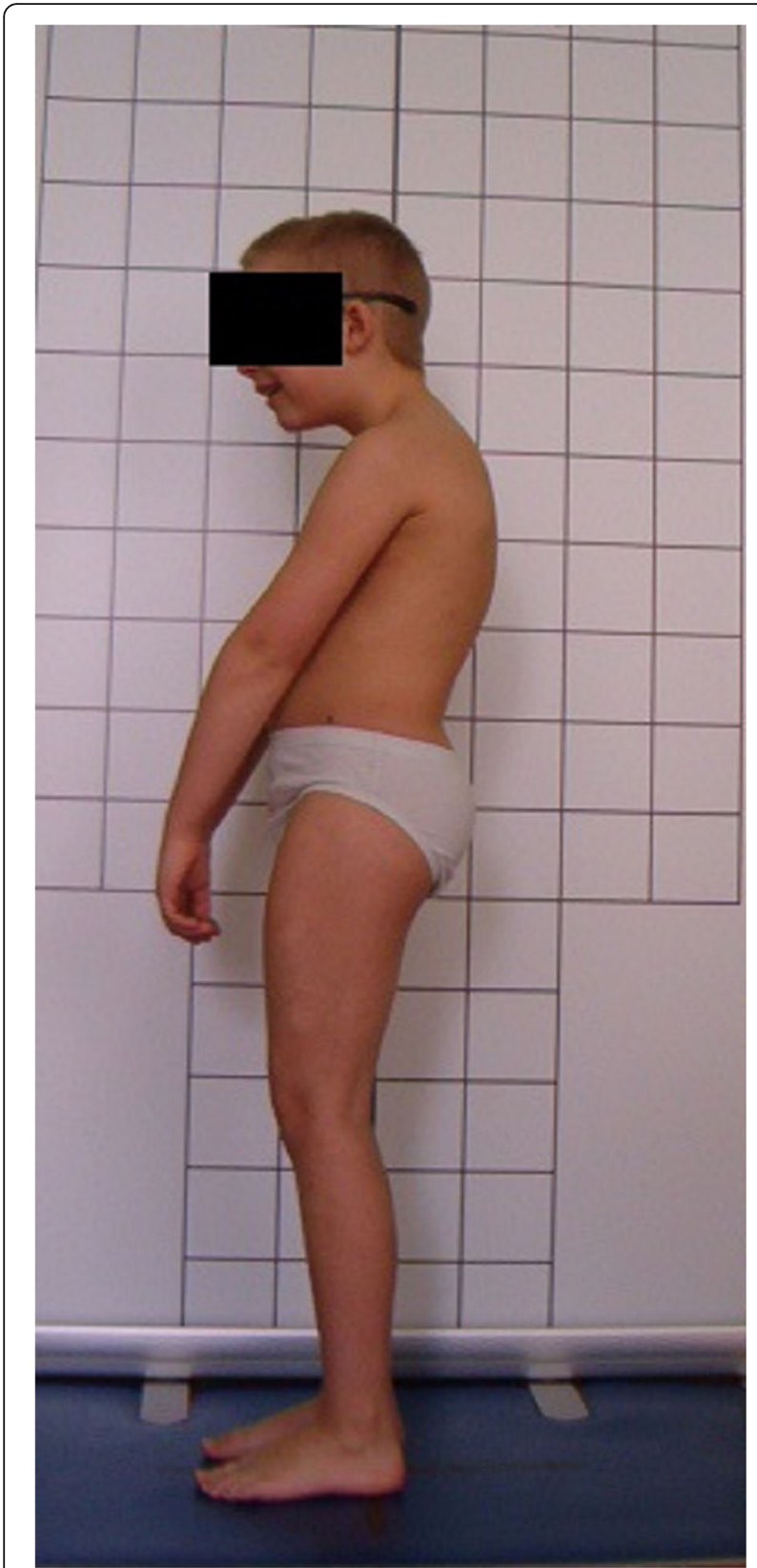

Fig. 24 Technical error-limited communication with child

We decided to position the feet over the longitudinal and crosswise lines marked on the ground so that the lateral malleoli were situated over the center of crosswise line, and the feet were parallel to the longitudinal line and hip-width apart. We found such setting to be the most neutral feet position which does not interfere with the spontaneous posture [63]. It has also the advantage of being suitable for assessing the tibio-calcaneal angle. In our experiments, most children needed assistance to place the feet correctly.

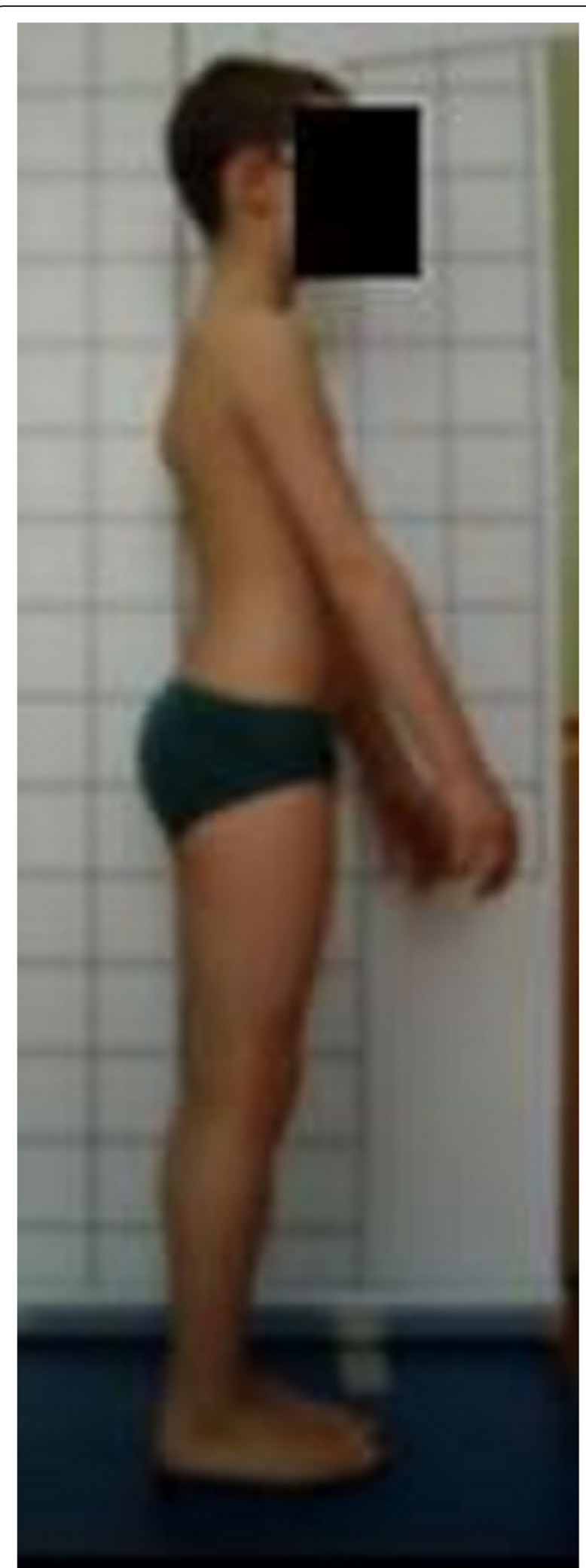

Fig. 25 Technical error-photo taken without proper focusing 


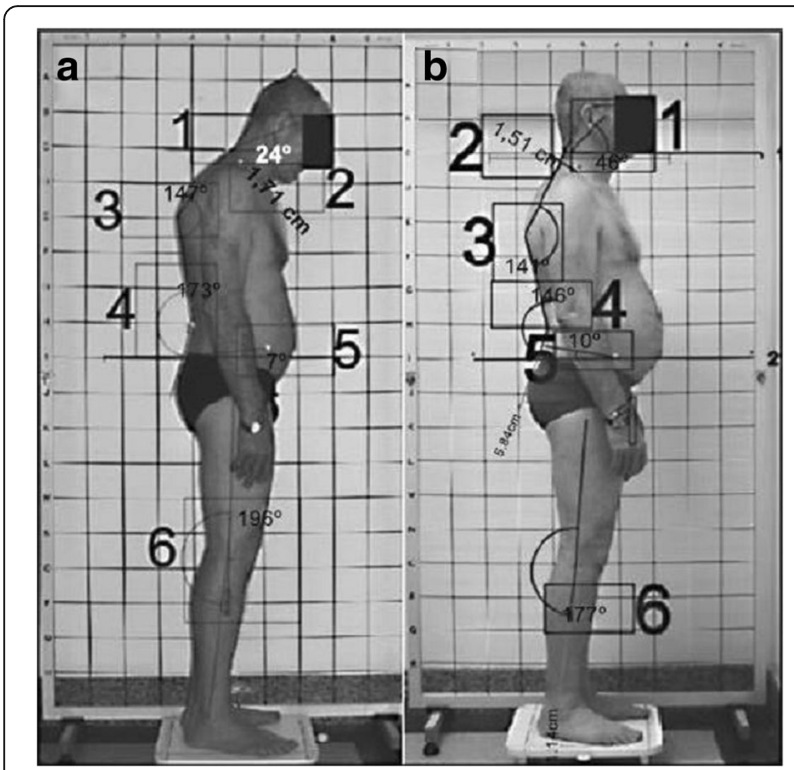

Fig. 26 a-b Photographic assessment as proposed by Canales et al. in 2010 ([69], reprinted by permission)

\section{Lower limbs positioning-the knees}

The position of the knee joint and the symmetric lower limbs loading are also objects for standardization as some children tend to stand for the photographic evaluation having one lower limb more loaded or one knee more visibly bended. Such a position would influence the whole body posture, especially the trunk. We recommend positioning the child with equally loaded feet, in neutral setting of the knees, without flexion or hyperextension.

\section{Upper limb positioning-the elbows}

Most authors suggest using the position with upper limbs hanging loosely [87, 96, 98, 102, 104, 105] in order not to influence the trunk [106]. The problem of the upper limb positioning is well-studied in the case of lateral spine radiography and different solutions are proposed to avoid the spine being obscured by the upper limbs [106-108]. Moreover, in the course of the standardization studies, we observed that the relaxed upper limbs sometimes covered the lumbar lordosis contour and greater trochanter. Similar observations have been made by other authors who suggested carrying out photographic sagittal evaluation with the elbow joints bent at $90^{\circ}[73,87,109]$. Finally, we recommend setting the upper limbs slightly flexed at about $10^{\circ}-20^{\circ}$ at the gleno-humeral joints and at about $20^{\circ}-30^{\circ}$ at the elbow joints. The movement of the upper limb flexion in the gleno-humeral and the elbow joints is performed slowly to avoid any involuntary trunk movement towards trunk hyperextension [87], which is the way to increasing

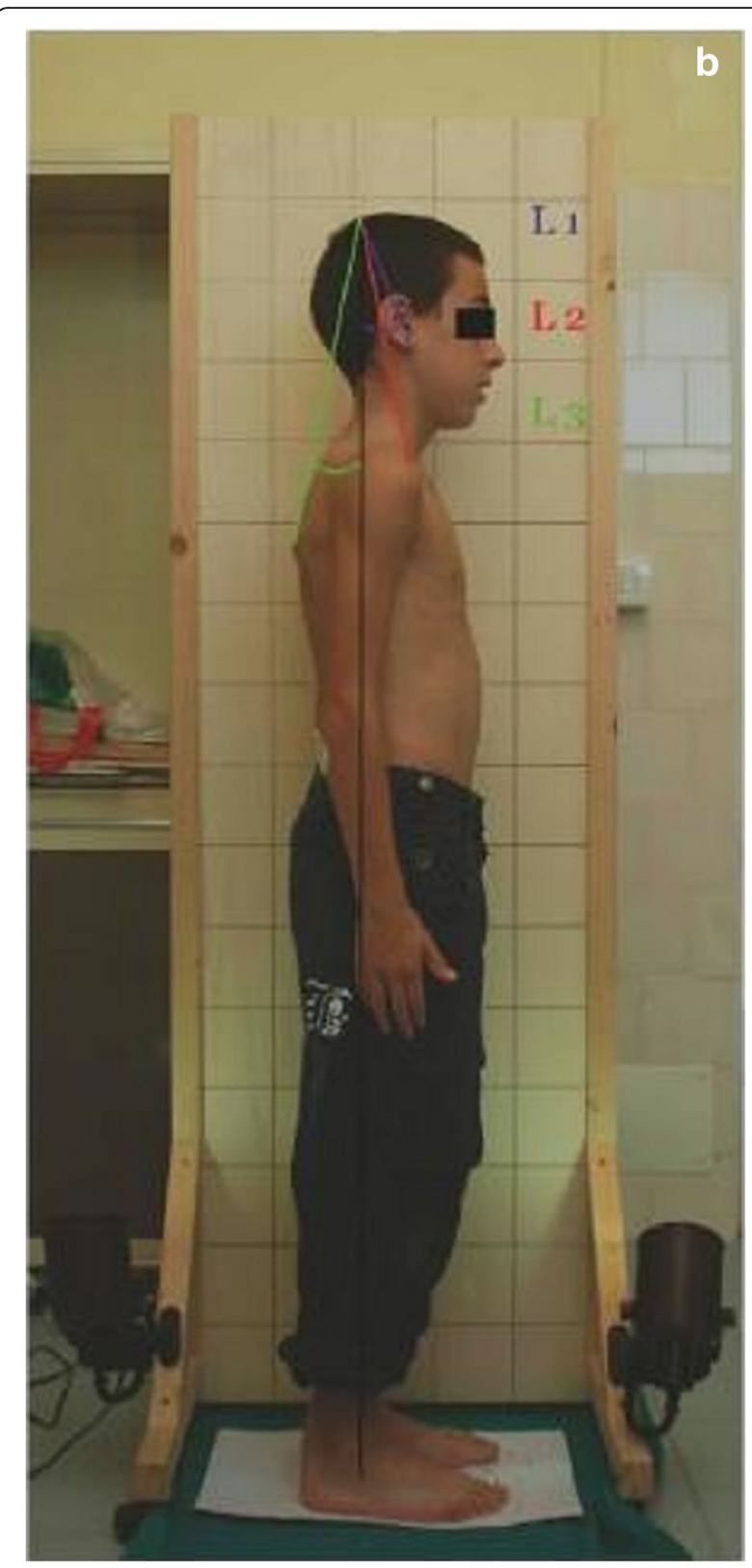

Fig. 27 Photographic assessment as proposed by Cerutto et al. in 2012 ([70], reprinted by permission)

lower thoracic spine [110] or even creating a pathological lordosis in this region [111]. During this movement, the child is watched, and if any accompanying trunk movement happens, the child is asked to repeat the upper limb movement. In some cases, passive positioning of the upper limbs is needed. In addition, we observed that during the upper limb movement, some children performed elevation or protraction of the shoulders which covered the neck contour and the upper thoracic spine contour. Therefore, during the positioning of the upper limbs, we make sure that the 


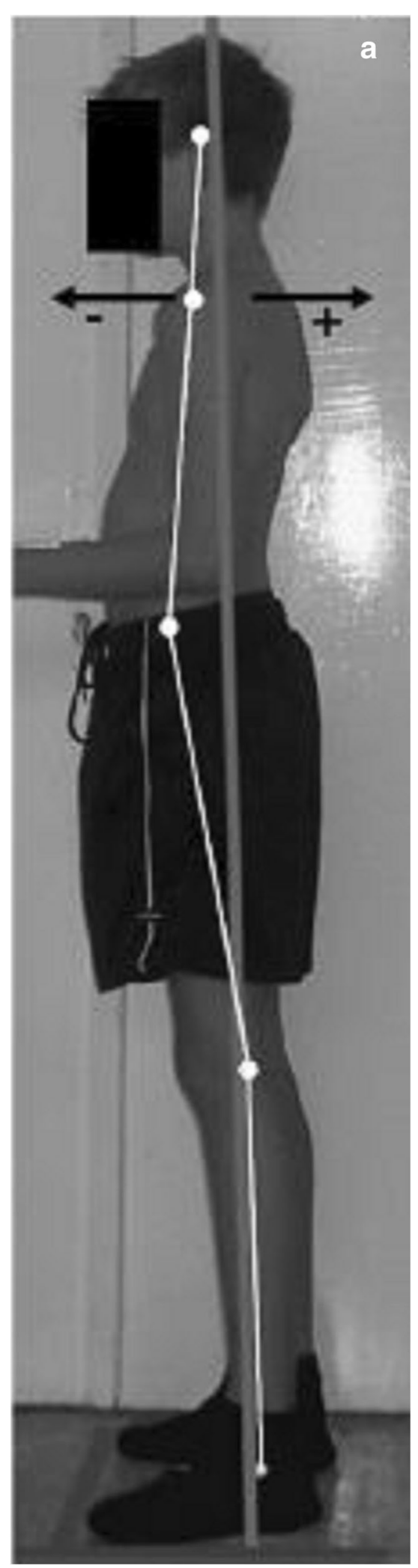

Fig. 28 Photographic assessment as proposed by Pausić et al. in 2010 ([71], reprinted by permission)

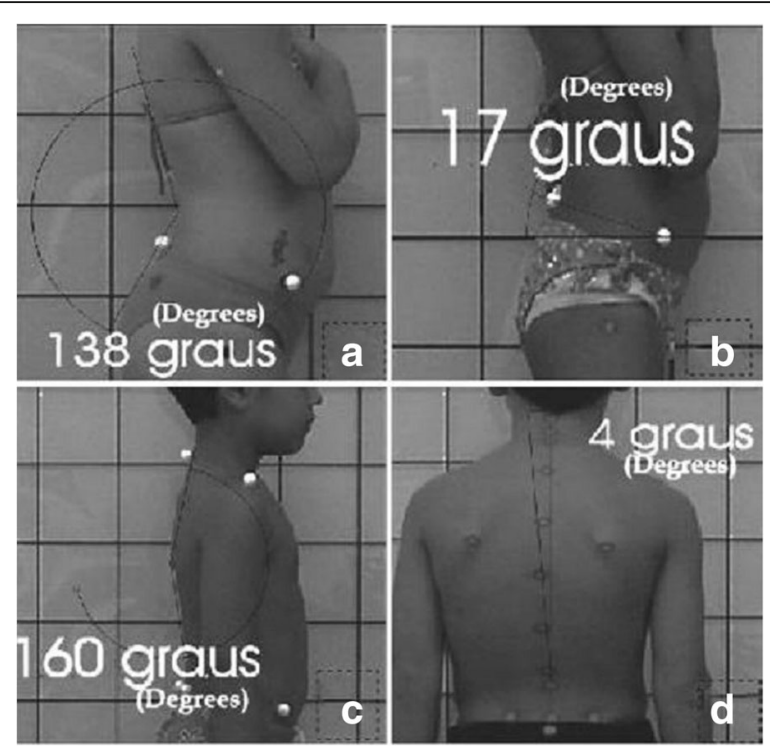

Fig. 29 a-d Photographic assessment as proposed by Penha et al. in 2009 ([8], reprinted by permission)

shoulder girdle stays down. It is important to note that the presence of shoulder protraction in loosely hanging upper limbs is common in the population of children aged $7-10[8]$.

\section{Head position and gaze direction}

During the standardization of the photographic technique, we checked the effect of the head position and the gaze direction on postural parameters. Our preliminary studies have shown that the head position affects the angular size of thoracic kyphosis and lumbar lordosis. Initially, we were planning to ask the child to look at a specific point marked in front of her/him as proposed in the literature [87]. Then, we noted this created an additional problem because of differences in children's height, which is why we proceeded with the "look ahead" command. Nevertheless, we noticed that some children, even when looking ahead, maintained voluntary lowered head position with the flexion of the cervical spine. Therefore, in order to achieve standardized conditions, each child was instructed to keep the eyes open and to direct the gaze at the eye level the moment it receives the "look ahead" command [71, 109, $112,113]$. Consequently, if an inappropriate voluntary head position was observed, we explained to the child once again how the head should be set. In rare situations, we helped the child by modifying the head position in a gentle way, trying not to trigger any artificially corrected position. In our practice, we also found it useful to ask children not to smile or laugh while taking the photos as it could affect postural parameters [112]. 


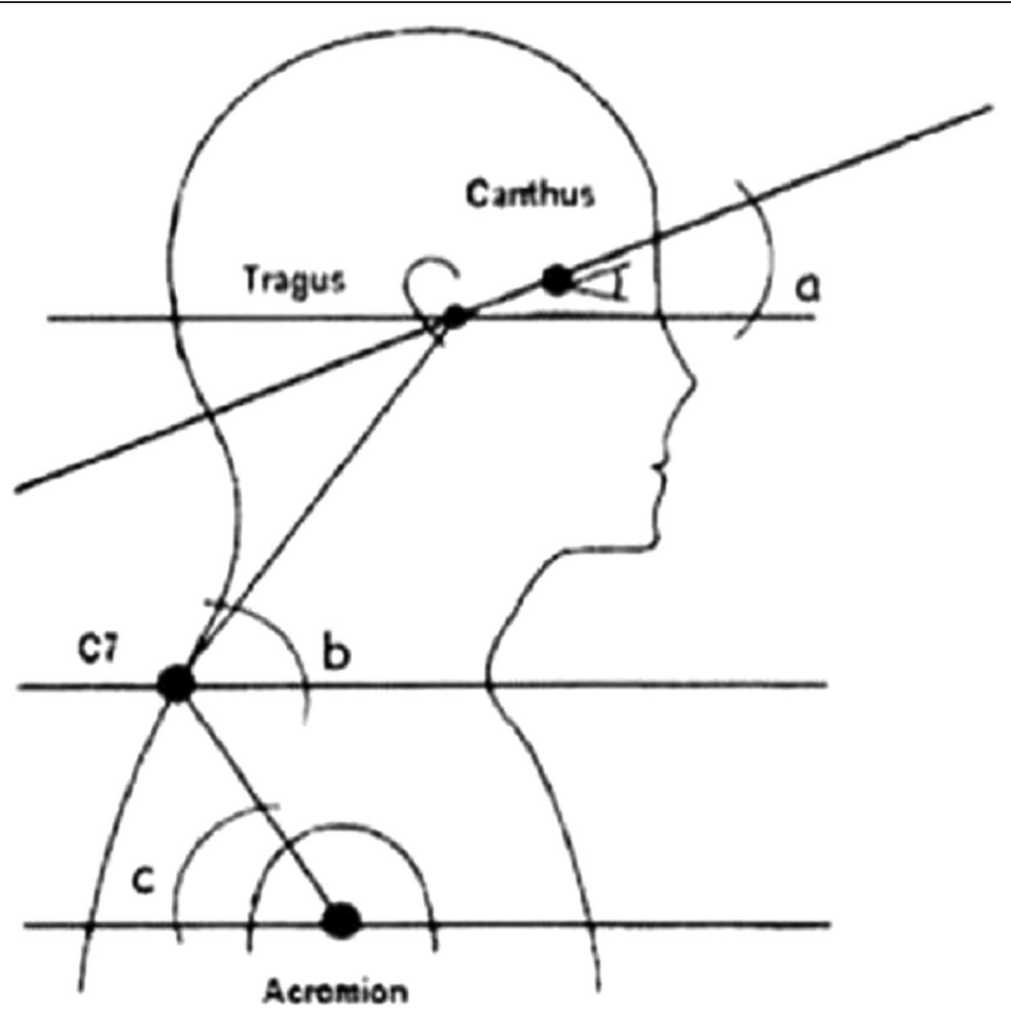

Fig. 30 Photographic assessment as proposed by Ruivo et al. in 2015 ([72], reprinted by permission)

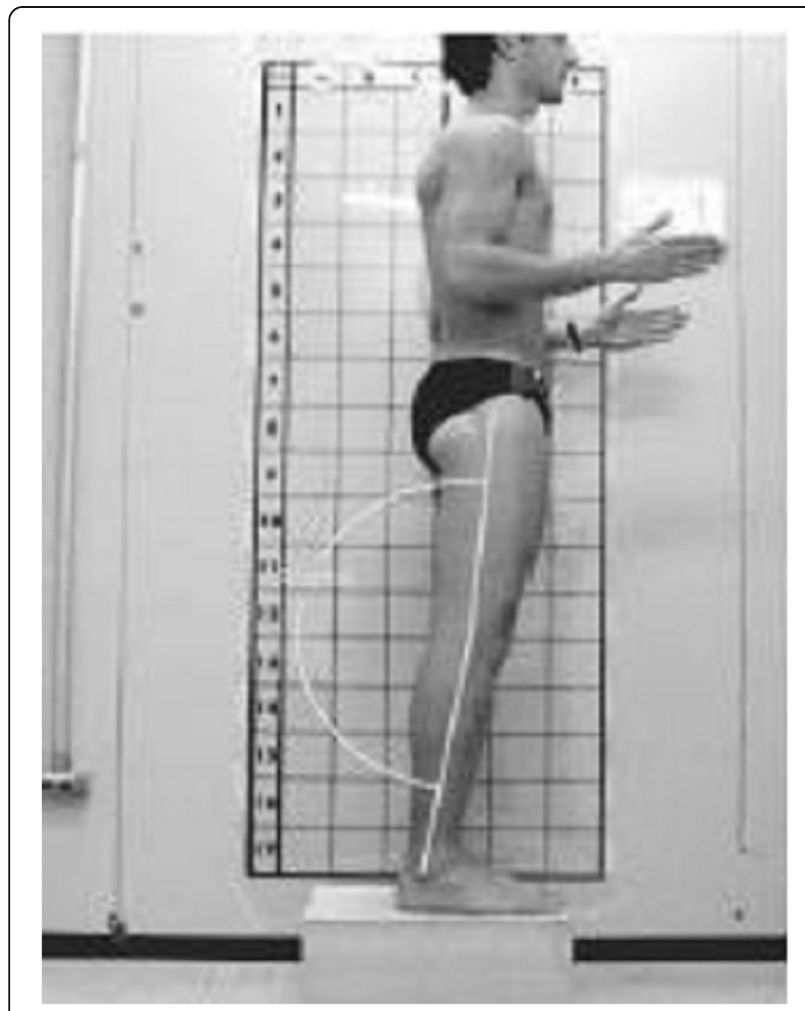

Fig. 31 Photographic assessment as proposed by Sacco et al. in 2007 ([73], reprinted by permission)
Digital photography technique for body posture evaluation and documentation

During this study, the postural photogrammetry revealed a simple and quick procedure. One can possibly perform photographic measurements with the use of a simple digital camera or a mobile camera in consideration of the standardized conditions for photographic evaluation. The tripod revealed a helpful device to stabilize the camera and control its position. The time needed for preparing the child for examination together with the time for taking photographic exposures in two sagittal projections was ca. $5 \mathrm{~min}$, whereas the time required for calculation of five standardized sagittal parameters was ca. $3 \mathrm{~min}$. This study confirmed the usefulness of photographic method for body posture documentation and evaluation. Digital photography technique can be used in research on the development and variability of posture in children. The developed procedure allows for the accurate and uniform filling of photographic documentation by physiotherapists and to obtain good quality research which is in line with the EBM rules. Due to its non-invasiveness, the technique can be promoted in scientific and clinical research. Parents' concerns regarding the use of radiography are avoided. The low cost of producing and archiving digital photos has a beneficial effect on technology. There is no need to acquire expensive, specialized equipment or software. Digital photogrammetry 


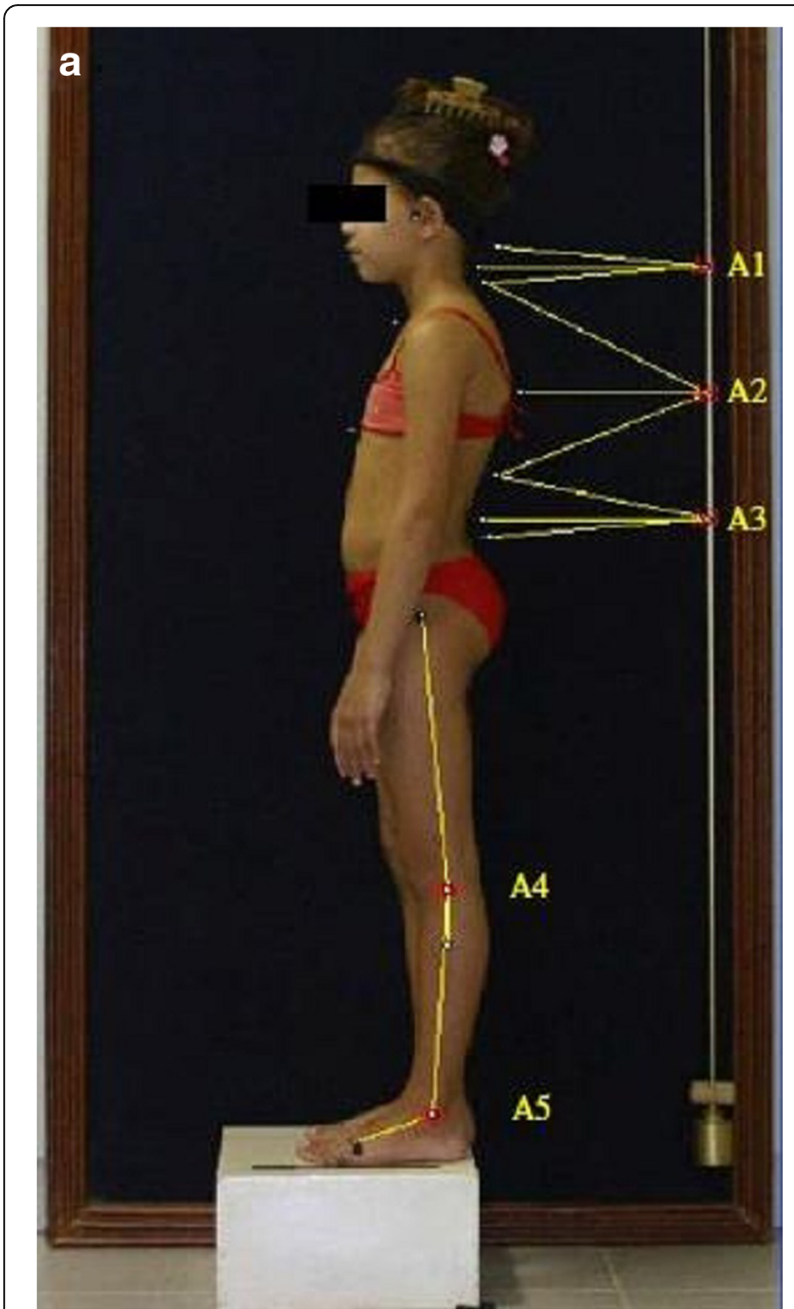

Fig. 32 Photographic assessment as proposed by Canhadas et al. in 2009 ([74], reprinted by permission)

screening can be significant for the budget savings of individual units which organize screening (e.g., the local government), which is often crucial in financing various types of research projects. Specific numerical values of the normal range for quantitative and validated parameters are presented in this paper. According to van Maanem et al.,

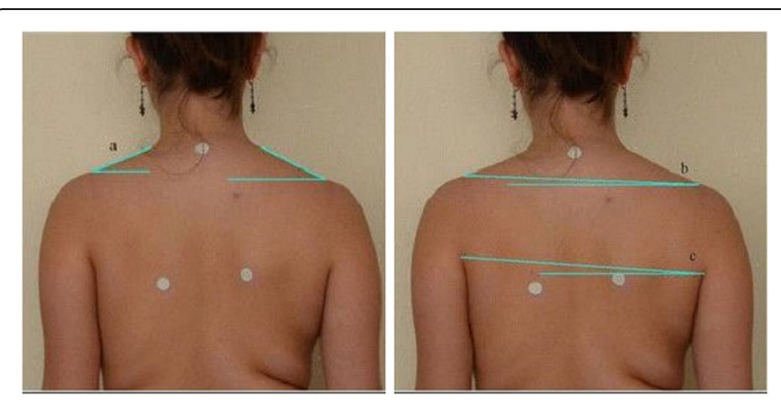

Fig. 34 Photographic assessment as proposed by Matamalas et al. in 2014 ([76], reprinted by permission)

the simplicity of assessing the posture on the photos is at the core of this technique-it is objective, easy to use, and of low cost [114]. For Cobb et al. [90], the digital photography for a two-dimensional assessment of the body shape is a valuable method for recording the body posture and calculating quantitative parameters in everyday clinical practice. Fortin et al. [109] claim that digital photography technique can be used for scientific assessment provided that the procedures in question are taken into account. Galera et al. mention that the current studies present new diagnostic possibilities of digital photography, which is a common procedure for two-dimensional evaluation of body posture [71]. Digital photography has some limitations. The major limitation of the technique is the two-dimensional body posture assessment, as it is not impossible to measure trunk rotation. The method may not be suitable for children under 7 years of age.

\section{Conclusions}

In summary, although both the surface topography and the radiological evaluation cannot be replaced with digital photography-the former for the 3D imaging, the latter for skeletal imaging-this technique offers a new additive value to human posture imaging. The development of digital photography technique allows for its regular use in the assessment of body posture. The method of child preparation and positioning described above allows us to avoid incidentally modified posture.

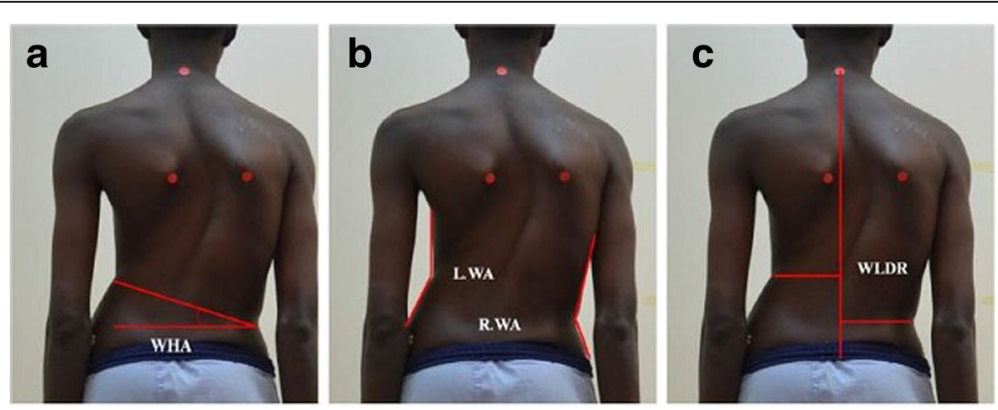

Fig. 33 a-c Photographic assessment as proposed by Matamalas et al. in 2016 ([75], reprinted by permission) 
The registration of images is simple, quick, harmless and cost-effective. The semi-automatic image analysis has been developed. The choice of postural parameters was based on previous publications and on personal experience and can be modified. The photographic method of body posture assessment developed during this study is characteristic of high reliability of measurements. The five developed and calculated photographic parameters (sacral slope, thoracic kyphosis, lumbar lordosis, chest inclination, and head protraction) describe the child body posture in the sagittal plane and demonstrate good repeatability and reproducibility, which may become a standard for body posture evaluation in children. Performing such a large series of measurements in children resulted in the preparation of normal values and percentile charts for age and sex, making it possible for us to employ the photographic parameters possible in the diagnosis of child posture pathology as well as to monitor the effects of corrective therapy.

\section{Additional files}

Additional file 1: Appendix 1. Coronal and sagittal photographic parameters. (PDF $268 \mathrm{~kb}$ )

Additional file 2: Appendix 2. Normative values of sagittal photographic parameters for children aged 7-10 based on the tables and percentile charts for sex and age. (PDF $1000 \mathrm{~kb}$ )

\section{Abbreviations \\ AA: Acromion-ankle angle; ASIS: Anterior superior iliac spine; ATSI: Anterior Trunk Symmetry Index; C7: Seventh cervical vertebra; Cl: Chest inclination angle; EA: Ear-ankle angle; EBM: Evidence-based medicine; FAI-A: Frontal Asymmetry Index at axilla level; FAl-C7: Frontal Asymmetry Index at C7 level; FAI-SN: Frontal Asymmetry Index at sternal notch level; FAl-T: Frontal Asymmetry Index at trunk level; HDl-A: Height Difference Index for axillas; HDI-S: Height Difference Index for shoulders; HDI-T: Height Difference Index for trunk waistline; HP: Head protraction angle; ICC: Intraclass correlation coefficient; IS: Idiopathic scoliosis; L1: First lumbar vertebra; L5: Fifth lumbar vertebra; LL: Lumbar lordosis angle; POTSI: Posterior Trunk Symmetry Index; PSIS: Posterior superior iliac spine; S1: First sacral vertebra; SEM: Standard error for single measurement; SPT: Sagittal pelvic tilt; SS: Sacral slope angle; T12: Twelfth thoracic vertebra; TA: Trochanter-ankle angle; TCA: Tibio- calcaneal angle; TFA: Tibio-femoral angle; TK: Thoracic kyphosis angle}

\section{Acknowledgements}

The authors would like to thank Prof. Pawel Ulman for his contribution to statistical analysis, Mr. Krzysztof Korbel, PT, and Ms. Katarzyna Politarczyk, PT, for assistance in the measurements.

The study was performed as part of the local prevention project "Skierniewice Chooses Health - Bad Posture and Postural Defects Prophylaxis in Class I-III Primary School Children" and "Poznan Chooses Health - Bad Posture Prophylaxis in Class I-IV Primary School Children".

\section{Funding}

No sources of funding were utilized for the study.

\section{Availability of data and materials}

The datasets analyzed during the current study can be requested from the corresponding author by providing a good reason.

\section{Authors' contributions}

LS performed the study design, developed the study protocol, data collection, and compilation, described the result analysis and manuscript, drafting and revision, critical revision of the manuscript. MK described result analysis, participated in the acquisition of the data, critical revision of the manuscript. DC performed the study design, developed the study protocol, data collection and compilation, described result analysis and manuscript, drafting and revision, critical revision of the manuscript. MT participated in the acquisition of the data and the critical revision of the manuscript. PC prepared the computer software for the study. NS developed the study protocol, critical revision of the manuscript, TK performed the study design, developed the study protocol, data collection and compilation, described result analysis and manuscript, drafting and revision, as well as the critical revision of the manuscript. All authors read and approved the final manuscript.

\section{Ethics approval and consent to participate}

All study participants gave written consent, and the study was approved by the Institutional Review Board of Poznan University of Medical Sciences (832/ 11, date 6/10/2011).

\section{Consent for publication \\ Not applicable.}

\section{Competing interests}

The authors declare that they have no competing interests.

\section{Publisher's Note}

Springer Nature remains neutral with regard to jurisdictional claims in published maps and institutional affiliations.

\section{Author details}

${ }^{1}$ Department of Spine Disorders and Pediatric Orthopedics, University of Medical Sciences, 28 Czerwca 1956r. no. 135/147, 61-545 Poznan, Poland. ${ }^{2}$ Rehasport Clinic, Poznan, Poland. ${ }^{3}$ Rehasport Clinic Licensed Rehabilitation Center, Skierniewice, Poland. ${ }^{4}$ Department of Physiotherapy, Józef Rusiecki University College, Olsztyn, Poland. ${ }^{5}$ Center of Body Posture, Olsztyn, Poland. ${ }^{6}$ Department of Orthopaedics, Pediatric Orthopaedics and Traumatology, The Centre of Postgraduate Medical Education in Warsaw, Otwock, Poland.

${ }^{7}$ Faculty of Health Studies, University of West Bohemia, Pilsen, Czech Republic. ${ }^{8}$ Faculty of Physical Education and Sport, Charles University, Prague, Czech Republic. ${ }^{9}$ ORTOTIKA, s. r. o, Faculty at Motol University Hospital, Prague, Czech Republic. ${ }^{10}$ Scoliosis Center, Medical Scanning Tokyo, Tokyo, Japan.

Received: 30 July 2017 Accepted: 4 December 2017

Published online: 19 December 2017

\section{References}

1. Kendall FP, McCreary EK, Provance PG. Muscles testing and function with posture and pain. 4th ed. USA: Lippincott Williams and Wilkins; 2005.

2. Kiebzak W, Szmigiel C, Kowalski I, Sliwinski Z. Importance of risk factors in detecting psychomotor development disorders in children during their first year of life. Advances in Rehabilitation. 2008;22:29-33.

3. Blaszczyk JW, Cieslinska-Swider J, Plewa M, Zahorska-Markiewicz B, Markiewicz A. Effects of excessive body weight on postural control. J Biomech. 2009;42:1295-300. https://doi.org/10.1016/j.jbiomech.2009.03.006.

4. Kowalski IM, Protasiewicz-Falowska H. Trunk measurements in the standing and sitting posture according to evidence based medicine (EBM). J Spine Surg. 2013;1:66-79.

5. Kowalski IM, Protasiewicz-Faldowska H, Siwik P, Zaborowska-Sapeta K, Dabrowska A, Kluszczynski M, Raistenskis J. Analysis of the sagittal plane in standing and sitting position in girls with left lumbar idiopathic scoliosis. Pol Ann Med. 2013;20:30-4. https://doi.org/10.1016/j.poamed.2013.07.001.

6. Komro KA, Tobler AL, Delisle AL, O'Mara RJ, Wagenaar AC. Beyond the clinic: improving child health through evidence-based community development. BMC Pediatr. 2013;13:172. https://doi.org/10.1186/1471-2431-13-172.

7. Sitarz K, Senderek T, Kirenko J, Olszewski J, Taczala J. Sensomotoric development assessment in 10 years old children with posture defects. Polish. J Phys. 2007:3:232-40.

8. Penha $P$, Joao $S$, Casarotto $R$, Amino $C$, Penteado D. Postural assessment of girls between 7 and 10 years of age. Clinics. 2005;60:9-16. 
9. Vrtovec T, Pernus F, Likar B. A review of methods for quantitative evaluation of spinal curvature. Eur Spine J. 2009;18:593-607. https://doi.org/10.1007/ s00586-009-0913-0.

10. Vrtovec T, Janssen MMA, Likar B, Castelein RM, Viergever MA, Pernus F. A review of methods for evaluating the quantitative parameters of sagittal pelvic alignment. Spine J. 2012;12:433-46. https://doi.org/10.1016/j.spinee. 2012.02.013.

11. Gangnet N, Pomero V, Dumas R, Skalli W, Vital JM. Variability of the spine and pelvis location with respect to the gravity line: a three-dimensional stereoradiographic study using a force platform. Surg Radiol Anat. 2003;25: 424-33. https://doi.org/10.1007/s00276-003-0154-6.

12. Lamartina C, Berjano P. Classification of sagittal imbalance based on spinal alignment and compensatory mechanisms. Eur Spine J. 2014;23:1177-89. https://doi.org/10.1007/s00586-014-3227-9.

13. Araujo F, Lucas R, Alegrete N, Azevedo A, Barros H. Individual and contextual characteristics as determinants of sagittal standing posture: a population-based study of adults. The Spine J. 2014;14:2373-83. https://doi. org/10.1016/j.spinee.2014.01.040.

14. Gorecki A, Kiwerski J, Kowalski IM, Marczynski W, Nowotny J, Rybicka M, Jarosz U, Suwalska M, Szelachowska-Kluza W. Prophylactics of postural deformities in children and youth carried out within the teaching environment-experts recommendations. Pol Ann Med. 2009;16:168-77.

15. Czaprowski D, Pawlowska P, Gebicka A, Sitarski D, Kotwicki T. Intra- and interobserver repeatability of the assessment of anteroposterior curvatures of the spine. using Saunders digital inclinometer Ortop Traumatol Rehabil. 2012;14:145-53. https://doi.org/10.5604/15093492.992283.

16. Stolinski L, Kotwicki T, Czaprowski D, Chowanska J, Suzuki N. Analysis of the anterior trunk symmetry index (ATSI). Preliminary report. Stud Health Technol Inform. 2012;176:242-6.

17. Suzuki N, Inami K, Ono T, Kohno K, Asher MA. Analysis of posterior trunk symmetry index (POTSI) in scoliosis. Part 1. Stud Health Technol Inform. 1999:59:81-4. https://doi.org/10.3233/978-1-60750-903-5-81.

18. Inami K, Suzuki N, Ono T, Yamashita Y, Kohno K, Morisue H. Analysis of posterior trunk symmetry index (POTSI) in scoliosis. Part 2. Stud Health Technol Inform. 1999;59:85-8.

19. Culik J, Marik I. Nomograms for determining the tibia-femoral angle. Locomotor System J. 2002;9:81-90.

20. Cheng J, Chan P, Chiang S, Hui P. Angular and rotational profile of the lower limb in 2,630 Chinese children. J Pediatr Orthop. 1991;11:154-61.

21. Fortin C, Feldman DE, Cheriet F, Denis E, Gravel D, Gauthier F, Labelle H. Reliability of a quantitative clinical posture assessment tool among persons with idiopathic scoliosis. Physiotherapy. 2012;98:64-75. https://doi.org/10. 1016/j.physio.2010.12.006.

22. Wiltse LL, Winter RB. Terminology and measurement of spondylolisthesis. J Bone Joint Surg. 1983;65:768-72.

23. Stagnara P, DeMauroy JC, Dran G, Gooon GP, Costanzo G, Dimnet J, Pasquet A. Reciprocal angulation of vertebral bodies in a sagittal plane: approach to references for the evaluation of kyphosis and lordosis. Spine. 1982;7:335-42

24. Boulay C, Tardieu C, Hecquet J, Benaim C, Mouilleseaux B,Marty C, PratPradal D, Legaye J, Duval-Beaupe're G, Pe' lissier J Sagittal alignment of spine and pelvis regulated by pelvic incidence: standard values and prediction of lordosis Eur Spine J 2006;15:415-422. doi: https://doi.org/10. 1007/s00586-005-0984-5.

25. Kuo YL, Tully EA, Galea MP. Video analysis of sagittal spinal posture in healthy young and older adults. J Manip Physiol Ther. 2009;32:210-5. https://doi.org/10.1016/j.jmpt.2009.02.002.

26. Bolzan GP, Souza JA, Boton LM, da Silva AMT, Corrêa ECR. Facial type and head posture of nasal and mouth-breathing children. J Soc Bras Fonoaudiol. 2011;23:315-20

27. Preece SJ, Willan P, Nester CJ, Graham-Smith P, Herrington L, Bowker P. Variation in pelvic morphology may prevent the identification of anterior pelvic tilt. J Man Manip Ther. 2008;16:113-7. https://doi.org/10.1179/ 106698108790818459.

28. Cerny P, Stolinski L, Drnkova J, Czaprowski D, Kosteas A, Marik I. Skeletal deformities measurements of $x$-ray images and photos on the computer. Locomotor System J. 2016;23(Suppl 2):32-6. ISSN 2336-4777.

29. Cerny P, Marik I. Anglespine-program for metrology of spinal and knee deformities in growth period. Locomotor System J. 2014;21:276-84.

30. Weir JP. Quantifying test-retest reliability using the intraclass correlation coefficient and the SEM. J Strength Cond Res. 2005;19:231-40.
31. Bland JM, Altman DG. Statistics notes: Cronbach's alpha. BMJ. 1997;314:572.

32. Keszei AP, Novak M, Streiner DL. Introduction to health measurement scales. J Psychosom Res. 2010;68:319-23. https://doi.org/10.1016/j.jpsychores.2010. 01.006.

33. Shrout PE, Fleiss JL. Intraclass correlations: uses in assessing rater reliability. Psychol Bull. 1979;86:420-8.

34. Knott P, Pappo E, Cameron M, deMauroy JD, Rivard C, Kotwicki T, Zaina F, Wynne J, Stikeleather L, Bettany-Saltikov GTB, Durmala J, Maruyama T, Negrini S, O'Brien JP, Rigo M. SOSORT 2012 consensus paper: reducing x-ray exposure in pediatric patients with scoliosis. Scoliosis. 2014;9:4. https://doi. org/10.1186/1748-7161-9-4.

35. Kotwicki T, Durmała J, Czaprowski D, Głowacki M, Kolban M, Snela S, Sliwinski Z, Kowalski IM. Conservative management of idiopathic scoliosis_guidelines based on SOSORT 2006 Consensus. Ortop Traumatol Rehabil. 2009;5:379-95.

36. Czaprowski D, Kotwicki T, Durmała J, Stolinski L. Physiotherapy in the treatment of idiopathic scoliosis - current recommendations based on the recommendations of SOSORT 2011 (society on scoliosis orthopaedic and rehabilitation treatment). Advances in Rehabilitation. 2014;1:23-9. https:// doi.org/10.2478/rehab-2014-0030.

37. Kotwicki T, Chowanska J, Kinel E, Czaprowski D, Tomaszewski M, Janusz P. Optimal management of idiopathic scoliosis in adolescence. Adolesc Health Med Ther. 2013;4:59-73. https://doi.org/10.2147/AHMT.S32088.

38. Richards SB, Vitale MG. Screening for idiopathic scoliosis in adolescents. An Information tatement J Bone Joint Surg. 2008;90:195-8. https://doi.org/10. 2106/JBJS.G.01276

39. Dutkowsky JP, Shearer D, Schepps B, Orton C, Scola F. Radiation exposure to patients receiving routine scoliosis radiography measured at depth in an anthropomorphic phantom. J Pediatr Orthop. 1990;10:532-4.

40. Fong DY, Lee CF, Cheung KM, Cheng JC, Ng BK, Lam TP, Mak KH, Yip PS, Luk KD. A meta-analysis of the clinical effectiveness of school scoliosis screening. Spine (Phila Pa 1976). 2010;35:1061-71. https://doi.org/10.1097/ BRS.0b013e3181bcc835.

41. Sabirin J, Bakri R, Buang SN, Abdullah AT, Shapie A. School scoliosis screening programme-a systematic review. Med J Malaysia. 2010;65:261-7.

42. Sox HC Jr, Berwick DM, Berg AO, Frame PS, Fryback DG, Grimes DA, Lawrence RS, Wallace RB, Washington AE, Wilson MEH, Woolf SH. Screening for adolescent idiopathic scoliosis: review article. JAMA. 1993;269:2667-72. https://doi.org/10.1001/jama.1993.03500200081038.

43. Bunnell WP. An objective criterion for scoliosis screening. J Bone Joint Surg. 1984;66:1381-7.

44. Balg F, Juteau M, Theoret C, Svotelis A, Grenier G. Validity and reliability of the iPhone to measure rib hump in scoliosis. J Pediatr Orthop. 2014;34:7749. https://doi.org/10.1097/BPO.0000000000000195.

45. Izatt MT, Bateman GR, Adam CJ. Evaluation of the iPhone with an acrylic sleeve versus the scoliometer for rib hump measurement in scoliosis. Scoliosis. 2012;7:14. https://doi.org/10.1186/1748-7161-7-14.

46. Driscoll M, Fortier-Tougas F, Labelle H, Parent S, Mac-Thong J. Evaluation of an apparatus to be combined with a smartphone for the early detection of spinal deformities. Scoliosis. 2014;25:10. https://doi.org/10.1186/1748-7161-910.

47. Grivas TB, Vasiliadis ES, Mihas C, Triantafyllopoulos G, Kaspiris A. Trunk asymmetry in juveniles. Scoliosis. 2008;3:13. https://doi.org/10.1186/17487161-3-13.

48. Kotwicki T, Chowanska J, Kinel E, Lorkowska M, Stryla W, Szulc A. Sitting forward bending position versus standing position for studying the back shape in scoliotic children. Scoliosis. 2007;2(Suppl 1):S34. https://doi.org/10. 1186/1748-7161-2-S1-S34.

49. McCarthy RE. Evaluation of the patient with deformity. In: Weinstein SL, editor. The pediatric spine. New York: Raven Press; 1994. p. 185-224.

50. Drerup B, Hierholzer E, Ellger B. Shape analysis of the lateral and frontal projection of spine curves assessed from rasterstereographs. In: Sevastik JA, Diab KM, editors. Research into spinal deformities. Amsterdam: IOS Press; 1997. p. 271-5.

51. Zubairi J. Applications of computer-aided rasterstereography in spinal deformity detection. Image Vis Comput. 2002;20:319-24.

52. Upadhyay SS, Burwell RG, Webb JK. Hump changes on forward flexion of the lumbar spine in patients with idiopathic scoliosis. Spine (Phila Pa 1976). 1988;13:146-51.

53. Turner-Smith AR, Harris JD, Houghton GR, Jefferson RJA. Method for analysis of back shape in scoliosis. J Biomech. 1988;21:497-509. 
54. Zonnenberg AJJ, Maanen V, Elvers JWH, Oostendorp RAB. Intra/interrater reliability of measurements on body posture photographs. J Craniomandibular Pract. 1996;14:326-31. https://doi.org/10.1080/08869634. 1996.11745985.

55. Raine S, Twomey LT. Head and shoulder posture variations in 160 asymptomatic women and men. Arch Phys Med Rehabil. 1997;78:1215-21. https://doi.org/10.1016/S0003-9993(97)90335-X

56. Vernon $\mathrm{H}$. An assessment of the intra- and inter-reliability of the posturometer. J Manipulative and Physiol Ther. 1983;6:57-60.

57. Bullock-Saxton J. Postural alignment in standing: a repeatable study. Austr J Physiother. 1993;39:25-9. https://doi.org/10.1016/S0004-9514(14)60466-9.

58. Braun BL, Amundson LR. Quantitative assessment of head and shoulder posture. Arch Phys Med Rehabil. 1989;70:322-9.

59. Grimmer K. An investigation of poor cervical resting posture. Aust J Physiother. 1997;43:7-16. https://doi.org/10.1016/S0004-9514(14)60398-6.

60. Nilsson BM, Soderlund A. Head posture in patients with whiplash-associated disorders and the measurement method's reliability - a comparison to healthy subjects. Adv Physiother. 2005;7:13-9. https://doi.org/10.1080/ 14038190510010278

61. Christensen HW, Nilsson N. The ability to reproduce the neutral zero position of the head. J Manip Physiol Ther. 1999;22:26-8. https://doi.org/10. 1016/S0161-4754(99)70102-8.

62. Swinkels A, Dolan P. Regional assessment of joint position sense in the spine. Spine. 1998;23:590-7.

63. Swinkels A, Dolan P. Spinal position sense is independent of the magnitude of movement. Spine. 2000;25:98-105.

64. Dunk NM, Chung YY, Compton DS, Callaghan JP. The reliability of quantifying upright standing postures as a baseline diagnostic clinical tool. J Manip Physiol Ther. 2004;27:91-6. https://doi.org/10.1016/j.jmpt.2003.12. 003.

65. Dunk NM, Lalonde J, Callaghan JP. Implications for the use of postural analysis as a clinical diagnostic tool: reliability of quantifying upright standing spinal postures from photographic images. J Manip Physiol Ther. 2005;28:386-92. https://doi.org/10.1016/j.jmpt.2005.06.006

66. Beaudoin L, Zabjek KF, Leroux MA, Coillard C, Rivard CH. Acute systematic and variable postural adaptations induced by an orthopaedic shoe lift in control subjects. Eur Spine J. 1999;8:40-5. https://doi.org/10.1007/ s005860050125.

67. Strimpakos N, Sakellari V, Gioftsos G, Papathanasiou M, Brountzos E, Kelekis D, Kapreli E, Oldham J. Cervical spine ROM measurements: optimizing the testing protocol by using a 3D ultrasound-based motion analysis system. Cephalgia. 2005;25:1133-45. https://doi.org/10.1111/j.1468-2982.2005.00970. $x$.

68. Zaina F, Atanasio A, Negrini S. Clinical evaluation of scoliosis during growth: description and reliability. In: Grivas TB, editor. The conservative scoliosis treatment. Studies in health technology and informatics, vol. 135. Amsterdam: IOS Press; 2008. p. 123-54.

69. Canales JZ, Cordas TA, Fiquer JT, Cavalcante AF, Moreno RA. Posture and body image in individuals with major depressive disorder: a controlled study. Rev Bras Psiquiatr. 2010;32:375-80. https://doi.org/10.1590/S151644462010000400010

70. Cerruto C, Di Vece L, Doldo T, Giovannetti A, Polimeni A, Goracci C. Computerized photographic method to evaluate changes in head posture and scapular position following rapid palatal expansion: a pilot study. J Clin Pediatr Dent. 2012;37:213-8. https://doi.org/10.17796/jcpd.37.2.11q670.

71. Pausic J, Pedisic Z, Dizdar D. Reliability of a photographic method for assessing standing posture of elementary school students. J Manip Physiol Ther. 2010;33:425-31. https://doi.org/10.1016/j.jmpt.2010.06.002.34vlw000wx.

72. Ruivo RM, Pezarat-Correia P, Carita Al. Intrarater and interrater reliability of photographic measurement of upper-body standing posture of adolescents. J Manip Physiol Ther. 2015;38:74-80. https://doi.org/10.1016/j.jmpt.2014.10. 009.

73. Sacco ICN, Alibert S, Queiroz BWC, Pripas D, Kieling I, Kimura AA, Sellmer AE, Malvestio RA, Sera MT. Reliability of photogrammetry in relation to goniometry for postural lower limb assessment. Rev Bras Fisioter. 2007;11: 411-7. https://doi.org/10.1590/\$1413-35552007000500013.

74. Canhadas Belli JF, Chaves TC, Siriani de Oliveira A, Grossi DB. Analysis of body posture in children with mild to moderate asthma. Eur J Pediatr. 2009; 168:1207-16. https://doi.org/10.1007/s00431-008-0911-y.

75. Matamalas A, Bago J, D'Agata E, Pellise F. Validity and reliability of photographic measures to evaluate waistline asymmetry in idiopathic scoliosis. Eur. Spine J. 2016;25:3170-9. https://doi.org/10.1007/s00586-0164509-1.

76. Matamalas A, Bago J, D'Agata E, Pellise F. Reliability and validity study of measurements on digital photography to evaluate shoulder balance in idiopathic scoliosis. Scoliosis. 2014;9:23. https://doi.org/10.1186/s13013-0140023-6.

77. Yoder J. Review: photographic architecture in the twentieth century, by Claire Zimmerman. J Soc Archit Hist. 2016;75:110-2. https://doi.org/10.1525/ jsah.2016.75.1.110.

78. Beilin H. Understanding the photographic image. J Appl Dev Psychol. 1999; 20:1-30. https://doi.org/10.1016/S0193-3973(99)80001-X.

79. Ellenbogen R, Jankauskas S, Collini FJ. Achieving standardized photographs in aesthetic surgery. Plast Reconstr Surg. 1990;86:955-61.

80. do R'r JLP, Nakashima IY, Rizopoulos K, Kostopoulos D, Marques AP. Improving posture: comparing segmental stretch and muscular chains therapy. Clin Chiropr. 2012;15:121-8. https://doi.org/10.1016/j.clch.2012.10. 039.

81. Santos MM, Silva MPC, Sanada LS, Alves CRJ. Photogrammetric postural analysis on healthy seven to ten-year-old children: interrater reliability. Rev Bras Fisioter. 2009;13:350-5. https://doi.org/10.1590/S141335552009005000047

82. Giglio CA, Volpon JB. Development and evaluation of thoracic kyphosis and lumbar lordosis during growth. J Child Orthop. 2007;1:187-93. https://doi. org/10.1007/s11832-007-0033-5.

83. do Rosário JLP. Photographic analysis of human posture: a literature review. J Bodyw Mov Ther. 2014;18:56-61. https://doi.org/10.1016/j.jbmt.2013.05.008.

84. Ferreira EAG, Duarte M, Maldonado EP, Burke TN, Marques AP. Postural assessment software (PAS/SAPO): validation and reliability. Clinics. 2010;65: 675-81. https://doi.org/10.1590/S1807-59322010000700005.

85. Neiva PD, Kirkwood RN, Godinho R. Orientation and position of head posture, scapula and thoracic spine in mouth-breathing children. Int J Pediatr Otorhinolaryngol. 2009;73:227-36. https://doi.org/10.1016/j.jporl. 2008.10.006

86. Grimmer-Somers K, Milanese S, Louw Q. Measurement of cervical posture in the sagittal plane. J Manip Physiol Ther. 2008;31:509-17. https://doi.org/10. 1016/j.jmpt.2008.08.005.

87. McEvoy MP, Grimmer K. Reliability of upright posture measurements in primary school children. BMC Musculoskelet Disord. 2005;6:35. https://doi. org/10.1186/1471-2474-6-35.

88. Gadotti IC, Magee DJ. Validity of surface measurements to access craniocervical posture in the sagittal plane: a critical review. Phys Ther Rev. 2008;13:258-68. https://doi.org/10.1179/174328808X309250.

89. Perry M, Smith A, Straker L, Coleman J, O'Sullivan P. Reliability of sagittal photographic spinal posture assessment in adolescents. Adv Physiother. 2008;10:66-75. https://doi.org/10.1080/14038190701728251.

90. Cobb SC, James R, Hjertstedt M, Kruk J. A digital photographic measurement method for quantifying foot posture: validity, reliability, and descriptive data. J Athl Train. 2011;46:20-30. https://doi.org/10.4085/10626050-46.1.20.

91. Guan X, Fan G, Wu X, Zeng Y, Su H, Gu G, Zhou Q, Gu X, Zhang H. Photographic measurement of head and cervical posture when viewing mobile phone: a pilot study. Eur Spine J. 2015;24:2892-8. https://doi.org/10. 1007/s00586-015-4143-3.

92. Matamalas A, Bago J, D' Agata E, Pellise F. Does patient perception of shoulder balance correlate with clinical balance? Eur Spine J. 2016;25:35607. https://doi.org/10.1007/s00586-015-3971-5.

93. Sai-hu M, Benlong S, Xu S, Zhen L, Ze-zhang Z, Bang-ping Q, Yong Q. Morphometric analysis of iatrogenic breast asymmetry secondary to operative breast shape changes in thoracic adolescent idiopathic scoliosis. Eur Spine J. 2016;25:3075-81. https://doi.org/10.1007/s00586-016-4554-9.

94. Saad KR, Colombo AS, Ribeiro AP, Joao SMA. Reliability of photogrammetry in the evaluation of the postural aspects of individuals with structural scoliosis. J Bodyw Mov Ther. 2012;16:210-6. https://doi.org/10.1016/j.jbmt. 2011.03.005.

95. Souza JA, Pasinato F, Basso D, Castilhos Rodrigues Correa E, Toniolo da Silva AM. Biophotogrammetry: reliability of measurementsobtained with a posture assessment software (SAPO). Rev Bras Cineantropom Desempenho Hum. 2011;13:299-305. https://doi.org/10.5007/1980-0037.2011v13n4p299.

96. Penha PJ, Baldini M, Amado João SM. Spinal postural alignment variance according to sex and age in 7- and 8-year-old children. J Manip Physiol Ther. 2009;32:154-9. https://doi.org/10.1016/j.jmpt.2008.12.009. 
97. Fortin C, Feldman DE, Cheriet F, Labelle H. Validity of a quantitative clinical measurement tool of trunk posture in idiopathic scoliosis. Spine. 2010;35: E988-94. https://doi.org/10.1097/BRS.0b013e3181cd2cd2.

98. Milanesi JM, Borin G, Corre^a ECR, da Silva AMT, Bortoluzzi DC, Souza JA. Impact of the mouth breathing occurred during childhood in the adult age: biophotogrammetric postural analysis. Int J Pediatr Otorhinolaryngol. 2011; 75:999-1004. https://doi.org/10.1016/j.jporl.2011.04.018.

99. Young S. Research for medical photographers: photographic measurement. J Audiov Media Med. 2002;25:94-8. https://doi.org/10.1080/ 014051102320376799.

100. Fortin C, Feldman DE, Cheriet F, Labelle H. Differences in standing and sitting postures of youth with idiopathic scoliosis from quantitative analysis of digital photographs. Phys Occup Ther Pediatr. 2013;33:1-14. https://doi. org/10.3109/01942638.2012.747582.

101. Galera S, Nascimento L, Teodoro E, Tomazini J. Comparative study on the posture of individuals with and without cervical pain. IFMBE Proc. 2009;25: 131-4. https://doi.org/10.1007/978-3-642-03889-1_36.

102. Lafond D, Descarreaux M, Normand MC, Harrison DE. Postural development in school children: a cross-sectional study. Chiropr Osteopat. 2007;15:1-7. https://doi.org/10.1186/1746-1340-15-1.

103. O'Sullivan PB, Grahamslaw KM, Kendell M, Lapenskie SC. Mo“ller NE, Richards $\mathrm{KV}$. The effect of different standing and sitting postures on trunk muscle activity in a pain-free population. Spine. 2002;27:1238-44.

104. Normand MC, Descarreaux M, Harrison DD, Harrison DE, Perron DL, Ferrantelli JR. Three dimensional evaluation of posture in standing with the posture print: an intra- and inter-examiner reliability study. Chiropr Osteopat. 2007;15:1-11. https://doi.org/10.1007/s00586-005-0984-5.

105. Smith A, O'Sullivan P, Straker L. Classification of sagittal thoraco-lumbopelvic alignment of the adolescent spine in standing and its relationship to low back pain. Spine. 2008;33:2101-7. https://doi.org/10.1097/BRS. 0b013e31817ec3b0

106. Vedantam R, Lenke $L G$, Bridwell $K H$, Linville $D L$, Blanke $K$. The effect of variation in arm position on sagittal spinal alignment. Spine. 2000;25:2204-9.

107. Tyrakowski M, Janusz P, Mardjetko S, Kotwicki T, Siemionow K. Comparison of radiographic sagittal spinopelvic alignment between skeletally immature and skeletally mature individuals with Scheuermann's disease. Eur Spine J. 2015:24:1237-43. https://doi.org/10.1007/s00586-014-3595-1.

108. Tyrakowski M, Mardjetko S, Siemionow K. Radiographic spinopelvic parameters in skeletally mature patients with Scheuermann disease. Spine (Phila Pa 1976). 2014;39:E1080-5. https://doi.org/10.1007/s00586-014-3595-1.

109. Fortin C, Feldman DE, Cheriet F, Labelle $H$. Clinical methods for quantifying body segment posture: a literature review. Disabil Rehabil. 2011;33:367-83. https://doi.org/10.3109/09638288.2010.492066.

110. Czaprowski D, Pawlowska P, Stolinski L, Kotwicki T. Active self-correction of back posture in children instructed with 'straighten your back' command. Man Ther. 2014;19:392-8. https://doi.org/10.1016/j.math.2013.10.005.

111. Stolinski L, Kotwicki T, Czaprowski D. Active self correction of child's posture assessed with plurimeter and documented with digital photography. Progress in Medicine. 2012;25:484-90.

112. Grimmer KA, Williams MT, Gill TK. The associations between adolescent head-on-eck posture, backpack weight and anthropometric features. Spine. 1999;24:2262-7.

113. Solow B, Sandham A. Cranio-cervical posture: a factor in the development and function of the dentofacial structures. Eur J Orthod. 2002;5:447-56. https://doi.org/10.1093/ejo/24.5.447.

114. Van Maanen CJ, Zonnenberg AJ, Elvers JW, Oostendorp RA. Intra/interrater reliability of measurements on body posture photographs. Cranio. 1996;14: $326-31$

\section{Submit your next manuscript to BioMed Central and we will help you at every step:}

- We accept pre-submission inquiries

- Our selector tool helps you to find the most relevant journal

- We provide round the clock customer support

- Convenient online submission

- Thorough peer review

- Inclusion in PubMed and all major indexing services

- Maximum visibility for your research

Submit your manuscript at www.biomedcentral.com/submit

) Biomed Central 